\title{
1 Glycan-dependent two-step cell adhesion mechanism of Tc toxins
}

2 Daniel Roderer ${ }^{1}$, Felix Bröcker ${ }^{2,3}$, Oleg Sitsel ${ }^{1}$, Paulina Kaplonek ${ }^{2}$, Franziska

3 Leidreiter $^{1,4}$, Peter H. Seeberger ${ }^{2}$ and Stefan Raunser, ${ }^{1, *}$

4

$5 \quad{ }^{1}$ Department of Structural Biochemistry, Max Planck Institute of Molecular Physiology,

6 Otto-Hahn-Str. 11, 44227 Dortmund, Germany

$7 \quad{ }^{2}$ Department of Biomolecular Systems, Max Planck Institute of Colloids and Interfaces,

8 Am Mühlenberg 1, 14476 Potsdam, Germany

9 3Present address: Vaxxilon Deutschland GmbH, Magnusstr. 11, 12489 Berlin,

10 Germany

$11{ }^{4}$ Present address: Department of Biomolecular Mechanisms, Max Planck Institute for

12 Medical Research, Jahnstraße 29, 69120 Heidelberg, Germany

$13 \quad{ }^{*}$ Correspondence: stefan.raunser@mpi-dortmund.mpg.de 
15 Abstract

16 Toxin complex (Tc) toxins are virulence factors widespread in insect and human

17 bacterial pathogens. Tes are composed of three subunits: TcA, TcB and TcC. TcA

18 facilitates receptor-toxin interaction and membrane permeation, $\mathrm{TcB}$ and $\mathrm{TcC}$

19 form a toxin-encapsulating cocoon. While the mechanisms of holotoxin assembly

20 and prepore-to-pore transition have been well-described, little is known about

21 receptor binding and cellular uptake of Tcs. Here, we identify two classes of

22 glycans, heparins/heparan sulfates and Lewis antigens, that act as receptors for

23 different TcAs from insect- and human pathogenic bacteria. Glycan array

24 screening and electron cryo microscopy (cryo-EM) structures reveal that all tested

25 TcAs bind unexpectedly with their $\alpha$-helical part of the shell domain to negatively

26 charged heparins. In addition, TcdA1 from the insect-pathogen Photorhabdus

27 luminescens binds to Lewis antigens with micromolar affinity. A cryo-EM

28 structure of the TcdA1-Lewis $X$ complex reveals that the glycan interacts with the

29 receptor-binding domain $D$ of the toxin. Our results suggest a two-step association

30 mechanism of Tc toxins involving glycans on the surface of host cells. 


\section{Introduction}

34 A widespread type of toxin in insect and human bacterial pathogens is the 35 heterotrimeric toxin complex $(\mathrm{Tc})^{1,2}$. Tc toxins were originally discovered in the insect 36 pathogen Photorhabdus luminescens, which lives in symbiosis with soil nematodes ${ }^{3}$.

37 Later, gene loci of Tc toxins were also found, amongst others, in Xenorhabdus nematophila ${ }^{4,5}$, in the facultative human-pathogen Photorhabdus asymbiotica ${ }^{6}$ and different species of Yersinia, which are both human and insect pathogens ${ }^{7,8}$.

is a homo-pentameric bell-shaped molecule that mediates target cell association, membrane penetration and toxin translocation ${ }^{9}$. TcA is made up of a central, pre-formed channel that is enclosed by an outer shell composed of a structurally conserved $\alpha$ helical domain decorated with variable receptor-binding domains (RBDs). The shell and channel are connected by a stretched linker ${ }^{10} . \mathrm{TcB}$ and $\mathrm{TcC}$ together form a $\sim 250 \mathrm{kDa}$ cocoon that encapsulates the toxic component, the $\sim 30 \mathrm{kDa}$ C-terminal hypervariable region (HVR) of TcC, which is autoproteolytically cleaved and resides inside the cocoon ${ }^{10,11}$. binding domain of $\mathrm{TcB}$, which is a distorted six-bladed $\beta$-propeller that closes the cocoon at the bottom. Following the contact of TcA and TcB, two blades of the $\beta$ propeller unfold and refold, resulting in the opening of the cocoon. As a consequence, 53 the toxic enzyme enters the translocation channel of $\mathrm{TcA}^{12}$. After specific binding to receptors on the surface of the target cell, the holotoxin 55 is endocytosed ${ }^{13}$. Acidification in the late endosome triggers the opening of the shell 56 and the compaction of the stretched linker drives the release of the channel from the 
shell and its entry into the target cell membrane. In the membrane the tip of the channel opens and enables the translocation of the actual toxin ${ }^{14,15}$. have been well-described (reviewed in ${ }^{16}$ ), little is known regarding the receptor binding and cellular uptake of Tc toxins. In the case of YenTcA, the TcA from the insect pathogen Yersinia entomophaga, two chitinases form a complex with the toxin ${ }^{17}$. It was proposed that the chitinases cause the degradation of the peritrophic membrane within the midgut of insects to facilitate toxin entry ${ }^{18}$. The association of YenTcA with target cells potentially occurs via glycan structures, which were recently identified in a binding screen to associate with both chitinases and directly with $\mathrm{YenTc}^{19}$. multiantennal glycans ${ }^{22}$. The structural similarity of the shell-enclosing RBDs of various TcAs to sialidase ${ }^{10,23}$ suggests that glycans could be also the cellular receptors in the case of TcAs that do not associate with chitinases.

Here, we used a synthetic glycan microarray ${ }^{24}$ to specifically screen for glycans as possible receptors for Tc toxins from several insect and human pathogens $(P$. luminescens TcdA1 (P1-TcdA1), X. nematophila XptA1 (Xn-XptA1), Morganella morganii TcdA4 (Mm-TcdA4), Y. pseudotuberculosis TcaATcaB (Yp-TcaATcaB)).

77 All tested TcAs interact with heparins/heparan sulfates (HS). The cryo-EM structure of Mm-TcdA4 in complex with heparin reveals that the glycan interacts directly with the $\alpha$-helical part of the shell domain. In addition, P1-TcdA1 interacts with several Lewis antigens, which bind to the RBD D as revealed by the cryo-EM structure of the PlTcdA1 in complex with BSA-Lewis X. 


\section{Results}

\section{Complex glycans on the cell surface mediate association of TcA.}

When intoxicating different cell types with Pl-TcdA1, we found that HEK 293 GnTI- $^{-}$ cells are less susceptible to the toxin than HEK 293T cells (Supplementary Figure 1a,b). While HEK 293T cells readily bind and accumulate fluorescently labeled P1-TcdA1 after one to four hours of incubation time, HEK $293 \mathrm{GnTI}^{-}$cells bind considerably less fluorescent P1-TcdA1 (Figure 1a,b). The major difference between the two cell types is

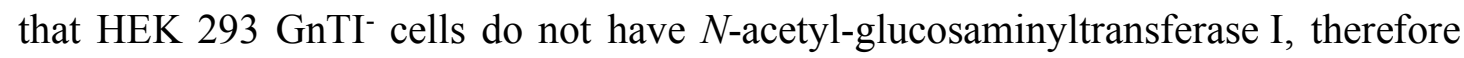
lack complex $\mathrm{N}$-glycans ${ }^{25}$. The lack of mature N-linked glycans on the plasma membrane of HEK $293 \mathrm{GnTI}^{-}$cells is probably responsible for the decreased interaction with P1-TcdA1, suggesting that $N$-linked glycans play a major role in the specific toxin binding to the host membrane.

To confirm that this is indeed the case, we treated HEK 293T cells with PNGase F to completely remove $N$-linked glycans on the plasma membrane ${ }^{26}$. PlTcdA1 binding to these cells was tremendously decreased supporting our conclusion that $N$-linked glycans are important for the binding of the toxin to host cells (Figure 1c, Supplementary Figure 1b).

\section{Pl-TedA1 binds to Lewis antigens}

In order to identify possible glycans that are responsible for the specific binding of Tc toxins to host cells, we first applied a synthetic glycan microarray and screened TcAs from different organisms, namely P1-TcdA1, Xn-XptA1, Mm-TcdA4, and YpTcaATcaB. We identified several Lewis oligosaccharides that interacted with P1TcdA1 (Figure 2a,b). Especially the trisaccharide Lewis $\mathrm{X}$ and the tetrasaccharides Lewis $\mathrm{Y}$ and sialyl-Lewis $\mathrm{X}$ interacted strongly with Pl-TcdA1 (Figure 2b,c, 
108 binding to the microarray even at higher protein concentrations, indicating that this 109 glycan-toxin interaction is specific for P1-TcdA1.

111 fucosylated glycans are normally found on the surface of human red blood cells ${ }^{27}$ and

112 not in insects. Therefore, it is unlikely that they represent the natural receptor of Pl-

113 TcdA1, which is a Tc toxin from an insect pathogenic bacterium. Although Lewis

114 antigens have not been described for insects, similar oligosaccharides with $\alpha 1,3-$

115 fucosylated Lewis-like antennae have been reported to be present in glycoproteins of

116 the lepidopterans Trichoplusia ni and Lymantria dispar ${ }^{28}$. Interestingly, Lepidoptera

117 are typical hosts of nematodes living in symbiosis with $P$. luminescens ${ }^{3}$ and are

118 therefore the natural target of Tc toxins. We therefore believe that the interaction 119 between Pl-TcdA1 and Lewis antigens is representative for the binding of the toxin to 120 similar glycan receptors on the insect host membrane.

121 Protein-glycan interactions are generally weak and multivalent interactions are 122 in many cases necessary to achieve a significant increase in receptor binding affinity ${ }^{29}$.

123 Since TcA is a homopentameric complex, high-affinity receptor binding is likely also 124 achieved by multivalency. To determine the binding kinetics of Lewis $\mathrm{X}$ antigens to 125 TcA pentamers, we conjugated multiple oligosaccharides to BSA as carrier protein 126 (Supplementary Figure 2b-d) and quantified the protein-oligosaccharide interaction 127 using biolayer interferometry (BLI). This approach mimics the high surface density of 128 glycans on a cell surface and thereby ensures that all Lewis $\mathrm{X}$ binding sites on a TcA 129 pentamer can be occupied. 
132 and off-rates of $3.8 \pm 0.4 \times 10^{4} \mathrm{M}^{-1} \mathrm{~s}^{-1}$ and $0.22 \pm 0.003 \mathrm{~s}^{-1}$, respectively, indicate a

133 highly dynamic binding equilibrium between Lewis $\mathrm{X}$ and Pl-TcdA1. This probably

134 provides the toxin with a certain mobility on the cell surface and allows it to laterally

135 move to regions with high receptor density.

\section{Structure of the PI-TcdA1-BSA-Lewis X complex}

138 To elucidate how Lewis $\mathrm{X}$ interacts with Pl-TcdA1, we planned to determine the

139 structure of the Pl-TcdA1-BSA-Lewis X complex by single particle cryo-EM. However,

140 since the affinity of P1-TcdA1 to BSA-Lewis X is low, high amounts of BSA-Lewis X

141 are required to allow for complex formation which is incompatible with single particle

142 cryo-EM. Therefore, we stabilized the P1-TcdA1-BSA-Lewis X complexes that were

143 formed using a large excess of BSA-Lewis X by crosslinking with glutaraldehyde and

144 removed unbound BSA-Lewis X. The resulting complexes were suitable for single

145 particle cryo-EM (Supplementary Figure 3a). Analyzing the single particles by two-

146 dimensional clustering and sorting in $\mathrm{SPHIRE}^{30}$ revealed up to three additional

147 densities corresponding to BSA-Lewis X at the periphery of P1-TcdA1, indicating that

148 the glycan interacts with one of the RBDs of the toxin (Figure 3a, Supplementary Figure

149 3b). Since not all five Lewis X binding sites of the Pl-TcdA1 pentamer are occupied

150 and the number of BSA-Lewis X molecules per complex varies, we combined three-

151 dimensional classification with symmetry expansion (Methods, Supplementary Figure

152 4) to obtain a three-dimensional reconstruction of the P1-TcdA1-BSA-Lewis X complex,

153 in which one BSA-Lewis X is bound to one Pl-TcdA1 pentamer (Figure 3b).

154 Despite the heterogeneity of the data set and the flexibility of the bound BSA-

155 Lewis $\mathrm{X}$ complex, the reconstruction reached an average resolution of $5 \AA$

156 (Supplementary Figure 3c-e). This enabled us to accurately fit the previously 
determined cryo-EM structure of Pl-TcdA1 into the toxin density ${ }^{23}$ (Figure 3c).

158 Although the density corresponding to BSA-Lewis X is less well resolved and therefore

159 the glycan or BSA cannot be fitted, its position on the toxin unambiguously 160 demonstrates that it binds to RBD D (Figure 3b,c, Supplementary Movie 1).

161 Molecular docking of the Lewis X trisaccharide on RBD D revealed two 162 prominent potential binding sites (Figure 3d, e, Supplementary Movie 1). Separated by 163 two tryptophan residues (W1720 and W1721), both binding sites form positively 164 charged grooves with many polar residues (predominantly Thr, Ser and Lys), allowing 165 hydrogen bond mediated interactions with the glycan.

TcAs of insect- and human-pathogenic bacteria bind to various heparins

168 To find out whether also heparins/heparan sulfates (HS) interact with the four different 169 TcAs, we performed a glycan screen comprising different heparins/HS 170 oligosaccharides. Heparins and HS are the most structurally complex 171 glycosaminoglycans and are a major component of the extracellular space ${ }^{31}$. They are 172 composed of disaccharide repeating units of D-glucosamine $(\mathrm{GlcN})$ and either 1173 iduronic acid (IdoA) or D-glucuronic acid (GlcA) linked by $\alpha 1-4$ and $\beta 1-4$ glycosidic 174 bonds, respectively. Sulfation can occur at positions 2, 3 and 6 of GlcN as well as at 175 position 2 of IdoA/GlcA. Heparin is primarily expressed in mast cells, while HS is 176 ubiquitous on cell surfaces and in the extracellular matrix. In heparin, uronic acid 177 residues are 90\% IdoA and 10\% its C5 epimer GlcA. The prototypical heparin 178 disaccharide contains three sulfate groups (2.7 sulfates per disaccharide on average in 179 the polymer). HS chains are typically more heterogeneous than those of heparin, are 180 richer in $\mathrm{N}$-acetyl D-glucosamine (GlcNAc) and GlcA and contain fewer O-sulfates 181 (one per disaccharide on average in the polymer). We found that all tested TcAs interact 
183 and Mm-TcdA4. The controls (wheat germ agglutinin and BSA) almost did not bind to

184 the microarray (Figure 4a), indicating that the heparin/HS-toxin interaction is indeed

185 specific. While the chain length of the strong binding heparins/HSs varies and seems

186 therefore not to be crucial for the interaction (Figure 4b), we observed that all of them

187 had at least two negative charges per monosaccharide group, suggesting that the binding

188 of TcA to heparins/HS is facilitated by electrostatic interactions.

\section{Structure of the Mm-TcdA4-heparin complex}

191 We chose Mm-TcdA4 from the opportunistic human pathogen Morganella morganii to investigate the heparin/HS-toxin interaction in more detail. First, we performed biolayer interferometry (BLI) to determine the affinity of Mm-TcdA4 to heparin/HS.

194 Since synthetic heparins/HSs are difficult to produce in large amounts needed for 195 biophysical and structural studies, we decided to work with natural $\sim 15 \mathrm{kDa}$ porcine 196 intestinal mucosa heparin instead, albeit its heterogeneity. The small apparent average 197 dissociation constant $\left(\mathrm{K}_{\mathrm{D}}\right)$ of the heparin mixture $(0.23 \pm 0.01 \mathrm{nM})$ clearly demonstrates 198 a high binding affinity of the glycans to Mm-TcdA4 (Supplementary Figure 5).

199 To identify which domains of Mm-TcdA4 are involved in heparin/HS binding, 200 we determined the structure of Mm-TcdA4 in complex with porcine intestinal mucosa 201 heparin using single particle cryo-EM (Supplementary Figure 6, Supplementary Movie 202 2). The $3.2 \AA$ structure is very similar to the previously obtained structure of Mm$203 \mathrm{TcdA}^{23}$ (Supplementary Figure 7a). However, we identified additional densities at the 204 periphery of the shell domain of each protomer (Figure 4c, Supplementary Figure 7b,c, 205 Supplementary Movie 2). The density occupies a cleft that is predominantly formed by 206 positively charged residues (R194, R195 K243, K265, R266 and R886), representing 
the ideal binding site for negatively charged heparins (Figure 4d). This clearly shows

208 that the heparins do not interact with an RBD, but directly with the $\alpha$-helical domain of

209 the shell. Although the resolution of the density does not allow to build an atomic model

210 in this region, we flexibly fitted several heparin oligosaccharides that resemble natural

211 heparin into the density. Indeed, most of them fit well and their negatively charged

212 residues are involved in many potential electrostatic interactions at the interface (Figure

2134 e, Supplementary Figure 7d).

\section{Discussion}

216 In the current work, we demonstrate that Tc toxins specifically interact with glycans on

217 the surface of host cells. We identified two specific types of glycans that act as receptors

218 for Tc toxin binding: heparins/HSs and Lewis antigens. While heparins bind to a

219 specific groove of the $\alpha$-helical shell domain of all tested TcAs, Lewis antigens only 220 interact with the RBD D of P1-TcdA1.

The heparin/HS binding site in the $\alpha$-helical shell domain is $10 \mathrm{~nm}$ away from

222 the membrane if the Tc toxin is in the prepore conformation and attaches perpendicular

223 to the membrane. HS proteoglycans form long polymers on cell surfaces that extend

$22420-150 \mathrm{~nm}$ from the plasma membrane ${ }^{32,33}$. Thus, they can easily bind to the toxin even

225 before it reaches the membrane surface. We propose that Tc toxins bind first to HS,

226 which brings them closer to the cell surface and thereby in contact with other surface

227 receptor molecules. HS also bind to viruses (e.g. baculovirus ${ }^{34}$ ) and cationic cell-

228 penetrating peptides ${ }^{35}$ that act as their respective receptors for cell entry.

229 Staphylococcus aureus beta-toxin uses the heparan sulfate carrying protein syndecan-1

230 as a cellular receptor ${ }^{36}$. 
Lewis antigens on the other hand are shorter glycans than the

232 glycosaminoglycans. Thus, the toxins have to be closer to the membrane in order to 233 interact with them. We therefore propose that Pl-TcdA1 binds in a second step to Lewis 234 antigens.

235 Because the five identical RBD Ds which interact with Lewis antigens are 236 symmetrically arranged at the bottom of the Pl-TcdA1 shell, the binding affinity is 237 highest when the toxin is oriented perpendicular to the membrane. This puts the toxin 238 in the ideal position for membrane penetration. Our data show that the interaction of 239 Pl-TcdA1 with BSA-Lewis X is highly dynamic, which could allow for the toxin to 240 move laterally on the membrane surface. Such an effect has been previously described 241 for bacteria and viruses that interact via lectins with the host cell surface ${ }^{32}$.

242 Lewis antigens are normally found on the surface of human red blood cells ${ }^{27}$ 243 and have been identified as receptors for toxins of human pathogens and viruses, such 244 as cholera toxin ${ }^{37}$ or norovirus ${ }^{38}$. However, Lewis-like oligosaccharides with core $\alpha 1,3-$ 245 fucosylation also have been identified in various insect species, making them likely 246 receptors for Tc toxins from entomopathogenic bacteria.

247 In a previous glycan array screen with the Tc toxin Yen-Tc from the insect 248 pathogen Yersinia entomophaga, 72 out of 432 glycans were identified as potential 249 toxin receptors, amongst them monosaccharides, fucosylated glycans, mannose 250 derivatives, glucose derivatives, sialylated derivatives, glycosaminoglycans, complex $251 N$-glycans and derivatives with terminal GlcNAc, GalNAc or galactose ${ }^{19}$. In contrast, 252 Xn-XptA1, Mm-TcdA4 and Yp-TcaATcaB only interacted strongly with heparins/HS 253 (11 out of 36 heparins/HS on the microarray). P1-TcdA1 additionally bound to core254 fucosylated Lewis antigens (6 out of 141 glycans on the microarray). This indicates that 
the chitinase-associated Yen-Tc is clearly less selective in terms of glycan binding than the TcAs that we tested here.

What about the other RBDs? Their structure is similar to RBD D, suggesting that they would also interact with glycans that we have not identified so far. There are three possible explanations why these interactions may have not been detected by our microarray screen. First, the distance between the glycans on the array surface and the

261 RBDs in the toxins differ from the situation on cell surfaces, where the glycans are 262 mostly bound to proteins. Therefore, possible glycan binding especially to RBDs that 263 locate distally to the membrane might be undetectable, especially when considering the 264 effect of multivalency in the pentameric TcA. Second, our glycan screen covers only a 265 selection of glycans that exist on target cells. For example multi-antennal glycans, 266 which have been described to function as high-affinity receptors for typhoid toxin ${ }^{22}$, 267 were not present in the array. Third, it could well be that several of the RBDs do not 268 bind to glycans on the cell surface, but directly to proteins. The removal of $N$-linked glycans on HEK 293T cells or the absence of complex glycans on HEK $293 \mathrm{GnTi}^{-}$cells reduced the number of Pl-TcdA1 toxins bound to the

271 cell surface when compared to untreated HEK 293T cells, but it did not completely 272 prevent toxin binding. This indicates that the toxin does not only bind to $N$-linked 273 glycans, but probably also interacts with $O$-linked glycans and/or directly with proteins 274 or lipids in the host cell membrane.

275 Taken together, our data allow us to propose the following model for Tc toxin 276 binding to cells (Figure 5). Initially, Tc toxins bind to long heparan sulfate 277 glycosaminoglycans to bring them into close contact to other surface receptor 278 molecules. In a second step, the toxin interacts with these receptors to orient the toxin 279 in an ideal position for membrane penetration. Next, the toxin undergoes endocytosis. 
280 Acidification in the late endosome triggers then the prepore-to-pore transition and

281 membrane permeation of TcA (Figure 5).

\section{Acknowledgements}

We thank Dr. O. Hofnagel and Dr. D. Prumbaum for excellent assistance in electron microscopy and acquisition of the datasets. We thank A. Elsner and K. VogelBachmayr for purification of Pl-TcdA1, Mm-TcdA4, and Pl-TcdB2-TccC3, 288 respectively, and M. Hülseweh for preparation of HEK cells. The authors would like to thank Dr. T. Wagner for aiding with Fiji, and M. Schulz for helping with flow cytometry. This work was supported by funds from the Max Planck Society (to S.R. and P.H.S.) and the European Research Council under the European Union's Seventh Framework Programme (FP7/2007-2013) (grant no. 615984) (to S.R.).

\section{Author Contributions}

295 S.R. and P.H.S. designed the project. D.R., O.S and F.L. prepared fluorescently labeled 296 TcAs for the glycan array and cellular experiments. F.B and P.K. carried out the glycan 297 arrays and interpreted the data. F.B. prepared the BSA-Lewis X adduct. D.R. analyzed 298 the affinities of proteins to glycans, performed flow cytometry experiments, prepared 299 cryo-EM samples, processed and analyzed the cryo-EM data. O.S. recorded and 300 analyzed confocal microscopy images. D.R., O.S., F.B. and P.K. prepared the figures. 301 All authors discussed the results and contributed in writing of the manuscript. 
bioRxiv preprint doi: https://doi.org/10.1101/857730; this version posted November 29, 2019. The copyright holder for this preprint (which

was not certified by peer review) is the author/funder, who has granted bioRxiv a license to display the preprint in perpetuity. It is made available under aCC-BY-NC-ND 4.0 International license.

304 The coordinates for the EM structures have been deposited in the Electron Microscopy

305 Data Bank under accession number ..... Correspondence and requests for materials

306 should be addressed to S.R. (stefan.raunser@mpi-dortmund.mpg.de). 


\section{Methods}

\section{Protein production}

$310 P$. luminescens TcdB2-TccC3 and P1-TcdA1 were expressed in BL21-

311 CodonPlus(DE3)-RIPL in 10 L LB medium and purified as described previously ${ }^{12}$. The

312 other TcAs (Xn-XptA1, Mm-TcdA4 and Yp-TcaATcaB were expressed in BL21-

313 CodonPlus(DE3)-RIPL and purified as described previously ${ }^{23}$. The expression plasmid

314 for PNGase F, pOPH6, was a gift from Shaun Lott (Addgene plasmid \#40315) and

315 PNGase $\mathrm{F}$ was expressed and purified as described previously ${ }^{39}$.

Labeling of TcAs for the glycan interaction screen

318 P1-TcdA1 was labeled with AlexaFluor488-C5-maleimide (Thermo Fisher, Cat. No. 319 A10254) in a 1:3 molar ratio in $20 \mathrm{mM}$ HEPES-NaOH pH 7.3, $150 \mathrm{mM} \mathrm{NaCl}, 0.05 \%$ 320 Tween 20 overnight at $4{ }^{\circ} \mathrm{C}$, resulting in fl-TcdA1. The other TcAs (Mm-TcdA4, Xn321 XptA1, Yp-TcaATcaB) were labeled with AlexaFluor488 NHS ester (Thermo Fisher, 322 Cat. No. A20000) in a 1:3 molar ratio in $20 \mathrm{mM}$ HEPES-NaOH pH 7.3, $150 \mathrm{mM} \mathrm{NaCl}$, $323 \quad 0.05 \%$ Tween-20 overnight at $4{ }^{\circ} \mathrm{C}$. Subsequently, unreacted labelling dye was removed 324 via size exclusion chromatography (SEC) on a Superose 6 Increase column (GE 325 Healthcare Life Sciences). All labeled proteins were flash-frozen in liquid nitrogen in 326 the presence of $35 \%$ glycerol and stored at $-80{ }^{\circ} \mathrm{C}$ until usage.

\section{Glycan interaction microarray}

Amine-functionalized oligosaccharides or natural heparin $(5 \mathrm{kDa})$ isolated from

330 porcine intestinal mucosae (Sigma-Aldrich) were immobilized on commercial $\mathrm{N}$ 331 hydroxysuccinimide (NHS) ester-activated microarray slides (CodeLink Activated 
332 Slides; SurModics, Eden Prairie, MN, USA) using a piezoelectric spotting device (S3;

333 Scienion, Berlin, Germany). Initial screening was performed with a comprehensive

334 microarray displaying a large library of oligosaccharide antigens (Supplementary Table

335 2), as described before ${ }^{40}$. The HS/heparin microarray has been published before ${ }^{41,42}$

336 (Supplementary Table 3). Other focused microarray slides that were used to confirm

337 initial hits contained oligosaccharides related to Lewis X. Samples for spotting were

338 diluted in $50 \mathrm{mM}$ sodium phosphate buffer, $\mathrm{pH}$ 8.5. Spotted slides were incubated in a

339 humid chamber for $24 \mathrm{~h}$ at room temperature to complete coupling reactions.

340 Remaining NHS ester groups were deactivated with $50 \mathrm{mM}$ ethanolamine in $50 \mathrm{mM}$

341 sodium phosphate buffer, $\mathrm{pH} 9$, for $1 \mathrm{~h}$ at $50{ }^{\circ} \mathrm{C}$. Slides were rinsed three times with

342 deionized water, dried by centrifugation ( $300 \mathrm{x} g, 5 \mathrm{~min})$ and stored desiccated until

343 use. Spotted and quenched microarray slides were blocked using $100 \mathrm{mM}$ (4-(2-

344 hydroxyethyl)-1-piperazineethanesulfonic acid (HEPES) pH 7.4 with $200 \mathrm{mM} \mathrm{NaCl}$

345 and $1 \%(\mathrm{w} / \mathrm{v})$ BSA (PBS-BSA) for $1 \mathrm{~h}$ at room temperature, washed three times with

$346100 \mathrm{mM}$ HEPES pH 7.4 with $200 \mathrm{mM} \mathrm{NaCl}$ and $0.05 \%$ (v/v) Tween-20 (wash buffer)

347 and dried by centrifugation. FlexWell 16 or FlexWell 64 grids (Grace Bio-Labs, Bend,

348 OR, USA) were applied to the slides to yield 16 or 64 wells for individual experiments,

349 depending on the printing patterns. Slides were incubated with samples diluted in 100

350 mM HEPES pH 7.4 with $200 \mathrm{mM} \mathrm{NaCl}, 0.01 \%$ (v/v) Tween-20 and $1 \%$ (w/v) BSA

351 for $1 \mathrm{~h}$ at room temperature in a humid chamber. Wells were washed three times using

352 wash buffer and rinsed once with deionized water. Grids were removed and slides were

353 dried by centrifugation $(300 \times g, 5 \mathrm{~min})$. The microarray slides were scanned with a

354 GenePix 4300A scanner (Molecular Devices; Sunnyvale, CA, USA). The

355 photomultiplier tube voltage was adjusted to reveal scans free of saturated signals.

356 Image analysis was carried out with the GenePix Pro 7 software supplied with the 
instrument. Background-subtracted mean fluorescence intensity (MFI) values were exported for further analysis.

\section{Conjugation of Lewis $\mathrm{X}$ and BSA}

We prepared a glycoconjugate composed of Lewis X trisaccharide (compound procedure is illustrated in Supplementary Figure 2b. First, 7 was combined with a 6-

364 fold molar excess of di-p-nitrophenyl adipate in $400 \mu \mathrm{L}$ anhydrous dimethyl sulfoxide 365 (DMSO)/pyridine $(2: 1)$ and $10 \mu \mathrm{L}$ triethylamine $\left(\mathrm{Et}_{3} \mathrm{~N}\right)$. The reaction mixture was

366 incubated for 2 hours at room temperature while stirring. Solvents were evaporated by 367 lyophilization. Dried reaction products were successively washed with 368 dichloromethane and chloroform (ten times $1 \mathrm{~mL}$ each) until thin-layer 369 chromatography (TLC) revealed complete removal of non-reacted crosslinker. The 370 washed reaction products were solubilized in DMSO, transferred to new reaction tubes 371 and lyophilized. Dried products were reacted with bovine serum albumin (BSA; Pan 372 Biotech) in $100 \mathrm{mM}$ sodium phosphate buffer, $\mathrm{pH} 8$, for $24 \mathrm{~h}$ at room temperature while 373 stirring. The resulting glycoconjugate was washed and concentrated with deionized 374 water using $10 \mathrm{kDa}$ centrifugal filter units (Merck Millipore, Tullagreen, Ireland).

375 Conjugation was confirmed by MALDI-TOF MS using an Autoflex Speed 376 system (Bruker Daltonics; Bremen, Germany). Samples were spotted using the dried 377 droplet technique with 2,5-dihydroxyacetophenone (DHAP) as matrix on MTP 384 378 ground steel target plates (Bruker Daltonics). Samples were prepared by mixing $2 \mu 1$ of 379 desalted protein sample with $2 \mu \mathrm{L}$ of DHAP matrix and $2 \mu \mathrm{L}$ of $2 \%(\mathrm{v} / \mathrm{v})$ 380 trifluoroacetic acid (TFA) prior to spotting. The mass spectrometer was operated in 381 linear positive mode. Mass spectra were acquired over an $\mathrm{m} / \mathrm{z}$ range from 30,000 to 
210,000 and data was analyzed with the FlexAnalysis software provided with the

383 instrument. The mass shift of about 14,500 Da showed that, on average, 20 molecules

384 of Lewis X were conjugated per molecule of BSA (Supplementary Figure 2c).

386 Biolayer interferometry (BLI)

387 The affinity of P1-TcdA1 to BSA-Lewis X was determined by BLI using an OctedRed 388384 (forteBio, Pall Life Sciences) and streptavidin biosensors. BSA-Lewis X was 389 biotinylated in $20 \mathrm{mM}$ HEPES-NaOH $\mathrm{pH} 7.3,150 \mathrm{mM} \mathrm{NaCl}, 0.05 \%$ Tween20 390 (labelling buffer) with NHS-LC-Biotin (Thermo Fisher, Cat. No. 21336) in a 1:3 molar 391 ratio for $2 \mathrm{~h}$ at room temperature. Unreacted biotin label was removed via SEC on a 392 Superdex 200 Increase column (GE Healthcare Life Sciences). Biotinylated BSA393 Lewis X was immobilized on streptavidin biosensors at $10 \mu \mathrm{g} / \mathrm{mL}$, and Pl-TcdA1 394 pentamer concentration in solution was $25-1600 \mathrm{nM}$. BLI sensorgrams were measured 395 in three steps: baseline (300 s), association (90 s), and dissociation (60 s). The 396 sensorgrams were corrected for background association of Pl-TcdA1 on unloaded 397 streptavidin biosensors. On- and off-rates of TcA binding were determined 398 simultaneously by a global curve fit according to a 1:1 binding model. All BLI steps 399 were performed in labelling buffer with $0.3 \mathrm{mg} / \mathrm{mL}$ BSA.

400 The affinity of Mm-TcdA4 to heparin was determined analogously using the 401 same instrument setup and buffers as described above. Biotinylated porcine intestinal 402 mucosa heparin (Merck Millipore) was immobilized on streptavidin biosensors at $40310 \mu \mathrm{g} / \mathrm{mL}$, and Mm-TcdA4 pentamer concentration in solution was $8-500 \mathrm{nM}$. BLI 404 sensorgrams were measured with $600 \mathrm{~s}$ association and $600 \mathrm{~s}$ dissociation time, and 405 corrected for background association of Mm-TcdA4 on unloaded streptavidin 
biosensors. On- and off-rates of TcA binding were determined simultaneously by a

407 global curve fit according to a 1:1 binding model.

\section{Deglycosylation of HEK293T cells}

$4105.5 \times 10^{6}$ HEK $293 \mathrm{~T}$ cells (Thermo Fisher) attached to $10 \mathrm{~cm}$ cell culture dishes

411 (Sarstedt) in DMEM/F12 + 10\% FBS medium were incubated with $20 \mu \mathrm{g}$ PNGase F

412 (self-prepared for flow cytometry, NEB Cat. No. P0704 for confocal microscopy) for

$4135 \mathrm{~h}$ at $37^{\circ} \mathrm{C}$. Subsequently, cells were detached from the surface by carefully

414 resuspending them, washed once in DMEM/F12 + FBS and resuspended in 1.8 mL PBS

415 immediately before subsequent intoxication and flow cytometry.

\section{Flow cytometry}

418 Immediately after deglycosylation and washing, HEK293T or HEK293 GnTI- cells $^{-}$

419 (Thermo Fisher) were incubated with $200 \mathrm{nM}$ (monomer concentration) TcdA1 labeled

420 with AlexaFluor488 for 15 min. Subsequently, cells were washed one time,

421 resuspended in PBS without toxin and injected into a LSRII flow cytometer (BD

422 Biosciences). 50000 cells were counted in total. Cell fluorescence caused by TcdA1

423 binding was analyzed using FlowJo.

\section{Intoxication assay}

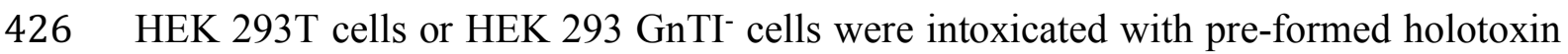

427 formed by P1-TcdA1 and PL-TcdB2-TccC3. Cells $\left(5 \times 10^{4}\right)$ were grown adherently in

$428400 \mu \mathrm{L}$ DMEM/F12 medium (Pan Biotech) overnight and 0.5 or $2 \mathrm{nM}$ holotoxin was

429 subsequently added. Incubation was performed for $16 \mathrm{~h}$ at $37^{\circ} \mathrm{C}$ before imaging. 
430 Experiments were performed in triplicate. Cells were not tested for Mycoplasma

431 contamination.

433 Confocal microscopy

434 Prior to confocal microscopy experiments, cells (HEK 293T and HEK $293 \mathrm{GnTI}^{-}$) were

435 seeded at a density of $0.3 \times 10^{6}$ cells per dish and grown on $35 \mathrm{~mm}$ poly-d-lysine coated 436 glass-bottom culture dishes (MatTek) until 30-40\% confluency in $2 \mathrm{~mL} \mathrm{DMEM/F12+}$ $43710 \%$ FBS for 36 hours in a $37^{\circ} \mathrm{C}, 5 \% \mathrm{CO}_{2}$ humidified atmosphere. Confocal imaging 438 was carried out at $37{ }^{\circ} \mathrm{C}$ in a $5 \% \mathrm{CO}_{2}$ atmosphere using a ZEISS LSM 800 microscope 439 equipped with a C-Apochromat 40x/1.2 W objective. After the initial image was taken 440 (0 h), AlexaFluor488 labelled TcdA1 was added to a final concentration of $500 \mathrm{pM}$. 441 Images were then taken at 10-minute intervals for 8 hours. The experiments were done 442 in three biological replicates for each cell type.

443 Images taken at 1 hour intervals were processed in Fiji ${ }^{44}$. A cell mask was 444 generated by using the Trainable Weka Segmentation plugin ${ }^{45}$ on the transmitted light 445 channel and then used to focus on the relevant areas of the fluorescent channel. The 446 mean grey values from the fluorescent channel were then measured for each image, 447 which represent the sum of all grey pixel values (fluorescence) in the selections divided 448 by the total number of pixels (cell surface). The autofluorescence for each replicate was 449 removed by subtracting the mean grey value of the initial $0 \mathrm{~h}$ image from later post450 intoxication images. The averages and standard deviation for this normalized mean 451 fluorescence intensity were then calculated and plotted. 
454 TcdA1 $(1 \mu \mathrm{M})$ and BSA-Lewis $\mathrm{X}(30 \mu \mathrm{M})$ were incubated in $20 \mathrm{mM}$ HEPES-NaOH

$455 \mathrm{pH} 8.0, \quad 150 \mathrm{mM} \mathrm{NaCl}, 0.02 \%$ Tween-20 overnight at $4{ }^{\circ} \mathrm{C}$. Subsequently, 456 glutaraldehyde was added to a final concentration of $0.1 \%$ and proteins were 457 crosslinked for $90 \mathrm{~min}$ at $22^{\circ} \mathrm{C}$. The reaction was stopped with $1.7 \mathrm{mM}$ Tris- $\mathrm{HCl} \mathrm{pH} 8.0$ 458 and crosslinked TcdA1-BSA-Lewis X was purified from excess of BSA-Lewis X by 459 SEC using a Superose 6 3.2-300 column (GE Healthcare Life Sciences).

\section{Cryo-EM sample preparation and data acquisition of TedA1-BSA-Lewis X}

$4 \mu \mathrm{L}$ of $0.06 \mathrm{mg} / \mathrm{mL}$ crosslinked complex were applied to glow-discharged holey carbon grids (Quantifoil, QF 1.2/1.3, 300 mesh) covered with a $2 \mathrm{~nm}$ carbon layer. After 10 min of incubation time on the grid, the grid was manually blotted and another $4 \mu \mathrm{L}$ were applied and incubated for $20 \mathrm{~s}$. Subsequently, the sample was vitrified in liquid ethane with a Cryoplunge3 (Cp3, Gatan) using 1.8 s blotting time at $90 \%$ humidity. Krios equipped with an XFEG and a Falcon III direct electron detector. Images were recorded using the automated acquisition program EPU (FEI) at a magnification of

471 movie-mode images were acquired in a defocus range of 1.0 to $2.5 \mu \mathrm{m}$. Each movie 472 comprised 40 frames acquired over $1.5 \mathrm{~s}$ with a total cumulative dose of $\sim 100 \mathrm{e}^{-} / \AA^{2}$.

\section{Image processing of TcdA1-BSA-Lewis $\mathbf{X}$}

475 After initial screening of all micrographs, 3878 integrated images were selected for

476 further processing. Movie frames were aligned, dose-corrected and averaged using

477 MotionCor2 ${ }^{46}$. CTF parameters were estimated using CTER $^{47}$, implemented in the 478 SPHIRE software package ${ }^{30}$. Initially, 4300 particles were manually picked and 2D 
class averages used as an autopicking template were generated using ISAC $^{48}$ in

481 (http://www.mrc-lmb.cam.ac.uk/kzhang).

Reference-free 2D classification and cleaning of the dataset was performed with

483 the iterative stable alignment and clustering approach ISAC in SPHIRE. ISAC was performed with a pixel size of $5.61 \AA$ /pixel on the particle level. The 'Beautifier' tool of SPHIRE was then applied to obtain refined and sharpened 2D class averages at the original pixel size, showing toxin particles with visible additional density at the TcA 487 pentamer, which corresponds to BSA-Lewis X (Figure 3a). 199,038 particles were 488 selected for subsequent 3D refinement. We applied our previous reconstruction of $P$. 489 luminescens TcdA1 (EMD-3645) as initial model after scaling and filtering it to $25 \AA$ 490 resolution and performed an initial 3D refinement in SPHIRE using Meridien with C5 491 symmetry. The density corresponding to the bound BSA-Lewis X appears only at very 492 low binarization threshold (Supplementary Figure 4). Therefore, we expanded the 493 symmetry of the input particle to C5 via the "symmetrize" option of SPHIRE, resulting 494 in 995,190 particles. Subsequently, we applied 3D sorting (Sort3D in SPHIRE) to the 495 symmetrized stack using a focused mask that comprises the lower part of the shell and 496 the additional densities. The resulting 3D classes showed $1-2$ additional densities 497 corresponding to BSA-Lewis X at different orientations. We next rotated the projection 498 parameters of the classes by $+72^{\circ}$ or $-72^{\circ}$ in order to orient the most pronounced 499 additional density to the same direction in all classes (Supplementary Figure 4). Finally, 500 after import of the rotated projection parameters and stack de-symmetrization, we ran 501 a local refinement in Meridien with $\mathrm{C} 1$ symmetry. The resolution of the final density 502 was estimated to $6.99 / 5.01 \AA$ according to FSC $0.5 / 0.143$ after applying a soft 503 Gaussian mask. The B-factor was set to $-80.0 \AA^{2}$ for sharpening. 


\section{Cryo-EM sample preparation and data acquisition of TcdA4 and heparin}

506 Incubation of Mm-TcdA4 with porcine mucosa heparin in solution resulted in 507 precipitation. Therefore, $3 \mu \mathrm{L}$ of $0.10 \mathrm{mg} / \mathrm{mL}$ TcdA4 in $20 \mathrm{mM}$ Tris- $\mathrm{HCl} \mathrm{pH} 8.0,250$ $508 \mathrm{mM} \mathrm{NaCl}, 0.05 \%$ Tween-20 was pre-applied on a glow-discharged holey carbon grid 509 (Quantifoil, QF 2/1, 300 mesh) covered with a $2 \mathrm{~nm}$ carbon layer. After $20 \mathrm{~s}$ of 510 incubation time on the grid, the grid was manually blotted and $3 \mu \mathrm{L}$ of $0.3 \mathrm{mg} / \mathrm{mL}$ 511 heparin from porcine intestinal mucosa (Millipore, Cat. No. 375095) applied and 512 incubated for $2 \mathrm{~min}$ at $22^{\circ} \mathrm{C}$. Subsequently, the sample was vitrified in liquid ethane 513 with a Cryoplunge3 (Cp3, Gatan) using $1.8 \mathrm{~s}$ blotting time at $89 \%$ humidity.

515 Molecular Physiology, Dortmund using a Cs corrected Titan Krios equipped with an 516 XFEG and a Falcon III direct electron detector. Images were recorded using the 517 automated acquisition program EPU (FEI) at a magnification of 59,000x, 518 corresponding to a pixel size of $1.11 \AA$ /pixel on the specimen level. 5549 movie-mode 519 images were acquired in a defocus range of 1.2 to $2.2 \mu \mathrm{m}$. Each movie comprised 40 520 frames acquired over $1.5 \mathrm{~s}$ with a total cumulative dose of $\sim 100 \mathrm{e}^{-/} \AA^{2}$.

522 Image processing of Mm-TcdA4-heparin

523 After initial screening of all micrographs, 4749 integrated images were selected for 524 further processing. Movie frames were aligned, dose-corrected and averaged using 525 MotionCor ${ }^{46}$. The integrated images were also used to determine the contrast transfer 526 function (CTF) parameters with $\mathrm{CTER}^{47}$, implemented in the SPHIRE software 527 package ${ }^{30}$. Initially, 4,300 particles were manually picked and 2D class averages used 528 as an autopicking template were generated using ISAC ${ }^{48}$ in SPHIRE. 477,602 particles 
529 were auto-picked from the images using Gautomatch (http://www.mrc-

$530 \quad$ lmb.cam.ac.uk/kzhang).

531 Reference-free 2D classification and cleaning of the dataset were performed

532 with the iterative stable alignment and clustering approach ISAC in SPHIRE. ISAC was

533 executed with a pixel size of $5.61 \AA$ /pixel on the particle level. The 'Beautifier' tool of

534 SPHIRE was then applied to obtain refined and sharpened 2D class averages at the

535 original pixel size, showing high-resolution features (Supplementary Figure 6b). From

536 the initial set of particles, the clean set used for 3D refinement contained 182,506

537 particles. We applied our previous $3.3 \AA$ reconstruction of M. morganii TcdA4 23

538 (EMD-10035) as an initial model after scaling and filtering it to $25 \AA$ resolution and

539 performed 3D refinement in SPHIRE using Meridien with imposed C5 symmetry. The

540 resolution of the final density was estimated to be $3.6 / 3.2 \AA$ according to FSC 0.5 /

5410.143 after applying a soft Gaussian mask. The B-factor was estimated to be $127.6 \AA^{2}$.

542 Local FSC calculation was performed using the Local Resolution tool in SPHIRE.

543 (Supplementary Figure 6e) and the electron density map was filtered according to its

544 local resolution using the 3-D Local Filter tool in SPHIRE.

545 The local resolution of the additional density corresponding to heparin was

546 however not sufficient to obtain a molecular model. We therefore filtered the map

547 obtained here and the M. morganii TcdA4 map without heparin to $5 \AA$ resolution,

548 normalized the maps and subtracted the filtered and normalized TcdA4 map without

549 heparin from the map with heparin. The difference density was filtered to $15 \AA$

550 resolution to visualize the density corresponding to heparin (Supplementary Figure 7a). 
553 We used AutoDock Vina ${ }^{49}$ via the UCSF Chimera plugin to visualize potential

554 conformations of heparin bound to Mm-TcdA4 and Lewis X bound to Pl-TcdA1.

555 Before docking, the interface regions of the proteins were protonated using $\mathrm{H}++^{50}$ at

$556 \mathrm{pH} 7.0$ and $150 \mathrm{mM}$ ionic strength. For Mm-TcdA4, we docked a heparin

557 pentasaccharide (molecule code NTP) after geometry optimization in phenix.elbow ${ }^{51}$

558 to the outer shell region of (residues $100-310$ and $443-984$ ). We chose the

559 conformation that fitted best into the additional density from the obtained docking

560 results. The resulting score of the docking pose was $-6.2 \mathrm{kcal} / \mathrm{mol}$. For Pl-TcdA1, we

561 docked the Lewis X trisaccharide to RBD D (residues 1638-1754). We chose two

562 representative conformations which are closely located to the additional density with 563 scores of $-4.5 \mathrm{kcal} / \mathrm{mol}$ each. 


\section{References}

566 1. Waterfield, N. R., Bowen, D. J., Fetherston, J. D., Perry, R. D. \& ffrench-

567 Constant, R. H. The tc genes of Photorhabdus: a growing family. Trends

568 Microbiol. 9, 185-191 (2001).

569 2. ffrench-Constant, R. \& Waterfield, N. An ABC guide to the bacterial toxin complexes. Advances in Applied Microbiology 58, 169-183 (Elsevier, 2005).

3. Bowen, D. et al. Insecticidal toxins from the bacterium photorhabdus luminescens. Science 280, 2129-2132 (1998).

4. Sergeant, M., Jarrett, P., Ousley, M. \& Morgan, J. A. W. Interactions of insecticidal toxin gene products from Xenorhabdus nematophilus PMFI296. Appl. Environ. Microbiol. 69, 3344-3349 (2003).

5. ffrench-Constant, R. H. \& Bowen, D. J. Novel insecticidal toxins from nematode-symbiotic bacteria. Cell. Mol. Life Sci. 57, 828-833 (2000).

6. Gerrard, J., Waterfield, N., Vohra, R. \& ffrench-Constant, R. Human infection with Photorhabdus asymbiotica: An emerging bacterial pathogen. Microbes and Infection 6, 229-237 (2004).

7. Tennant, S. M., Skinner, N. A., Joe, A. \& Robins-Browne, R. M. Homologues of insecticidal toxin complex genes in Yersinia enterocolitica biotype 1A and their contribution to virulence. Infect. Immun. 73, 6860-6867 (2005).

8. Waterfield, N., Hares, M., Hinchliffe, S., Wren, B. \& ffrench-Constant, R. The insect toxin complex of Yersinia. Adv. Exp. Med. Biol. 603, 247-257 (2007).

9. Gatsogiannis, C. et al. A syringe-like injection mechanism in Photorhabdus luminescens toxins. Nature 495, 520-523 (2013).

10. Meusch, D. et al. Mechanism of Tc toxin action revealed in molecular detail. Nature 508, 61-65 (2014).

11. Busby, J. N., Panjikar, S., Landsberg, M. J., Hurst, M. R. H. \& Lott, J. S. The $\mathrm{BC}$ component of $\mathrm{ABC}$ toxins is an RHS-repeat-containing protein encapsulation device. Nature 501, 547-550 (2013).

12. Gatsogiannis, C. et al. Tc toxin activation requires unfolding and refolding of a B-propeller. Nature 563, 209-213 (2018).

13. Lang, A. E. et al. Photorhabdus luminescens toxins ADP-ribosylate actin and RhoA to force actin clustering. Science 327, 1139-1142 (2010).

14. Gatsogiannis, C. et al. Membrane insertion of a Tc toxin in near-atomic detail. Nat. Struct. Mol. Biol. 23, 884-890 (2016).

15. Roderer, D., Hofnagel, O., Benz, R. \& Raunser, S. Structure of a Tc holotoxin pore provides insights into the translocation mechanism. Proc. Natl. Acad. Sci. U.S.A. 116, 23083-23090 (2019).

16. Roderer, D. \& Raunser, S. Tc Toxin Complexes: Assembly, Membrane Permeation, and Protein Translocation. Annu. Rev. Microbiol. 73, annurevmicro-102215-095531-265 (2019).

17. Landsberg, M. J. et al. 3D structure of the Yersinia entomophaga toxin complex and implications for insecticidal activity. Proc. Natl. Acad. Sci. U.S.A. 108, 20544-20549 (2011).

18. Busby, J. N. et al. Structural analysis of Chil Chitinase from Yen-Tc: the multisubunit insecticidal ABC toxin complex of Yersinia entomophaga. J. Mol. Biol. 415, 359-371 (2012).

19. Piper, S. J. et al. Cryo-EM structures of the pore-forming A subunit from the Yersinia entomophaga ABC toxin. Nat Commun 10, 1952 (2019). 
20. Yao, G. et al. N-linked glycosylation of SV2 is required for binding and uptake of botulinum neurotoxin A. Nat. Struct. Mol. Biol. 23, 656-662 (2016).

21. Bäckström, M. et al. Structural basis for differential receptor binding of cholera and Escherichia coli heat-labile toxins: Influence of heterologous amino acid substitutions in the cholera B-subunit. Mol. Microbiol. 24, 489-497 (1997).

22. Yang, Y. A. et al. In vivo tropism of Salmonella Typhi toxin to cells expressing a multiantennal glycan receptor. Nat Microbiol 3, 155-163 (2018).

23. Leidreiter, F. et al. Common architecture of Tc toxins from human and insect pathogenic bacteria. Sci Adv 5, eaax6497 (2019).

24. Broecker, F. \& Seeberger, P. H. in Methods in Molecular Biology 1518, 227240 (Springer New York, 2017).

25. Reeves, P. J., Callewaert, N., Contreras, R. \& Khorana, H. G. Structure and function in rhodopsin: high-level expression of rhodopsin with restricted and homogeneous $\mathrm{N}$-glycosylation by a tetracycline-inducible $\mathrm{N}$ acetylglucosaminyltransferase I-negative HEK293S stable mammalian cell line. Proc. Natl. Acad. Sci. U.S.A. 99, 13419-13424 (2002).

26. Maley, F., Trimble, R. B., Tarentino, A. L. \& Plummer, T. H. Characterization of glycoproteins and their associated oligosaccharides through the use of endoglycosidases. Anal. Biochem. 180, 195-204 (1989).

27. MARCUS, D. M. \& CASS, L. E. Glycosphingolipids with Lewis Blood Group Activity - Uptake by Human Erythrocytes. Science 164, 553-\& (1969).

28. Stanton, R. et al. The underestimated N-glycomes of lepidopteran species. Biochim Biophys Acta Gen Subj 1861, 699-714 (2017).

29. Kulkarni, A. A., Weiss, A. A. \& Iyer, S. S. Glycan-based high-affinity ligands for toxins and pathogen receptors. Medicinal Research Reviews 30, 327-393 (2010).

30. Moriya, T. et al. High-resolution Single Particle Analysis from Electron Cryomicroscopy Images Using SPHIRE. J Vis Exp 2017, e55448-e55448 (2017).

31. Stringer, S. E. \& Gallagher, J. T. Heparan sulphate. Int. J. Biochem. Cell Biol. 29, 709-714 (1997).

32. Cohen, M. Notable Aspects of Glycan-Protein Interactions. Biomolecules 5, 2056-2072 (2015).

33. Varki, A. et al. Proteoglycans and Sulfated Glycosaminoglycans. (2009).

34. Makkonen, K. E. et al. 6-O-and N-sulfated syndecan-1 promotes baculovirus binding and entry into mammalian cells. J. Virol. 87, 11148-11159 (2013).

35. Wallbrecher, R. et al. The stoichiometry of peptide-heparan sulfate binding as a determinant of uptake efficiency of cell-penetrating peptides. Cell. Mol. Life Sci. 71, 2717-2729 (2014).

36. Hayashida, A., Bartlett, A. H., Foster, T. J. \& Park, P. W. Staphylococcus aureus beta-toxin induces lung injury through syndecan-1. Am. J. Pathol. 174, 509-518 (2009).

37. Heim, J. B., Hodnik, V., Heggelund, J. E., Anderluh, G. \& Krengel, U. Crystal structures of cholera toxin in complex with fucosylated receptors point to importance of secondary binding site. Sci Rep 9, 12243-14 (2019).

38. Kubota, T. et al. Structural basis for the recognition of Lewis antigens by genogroup I norovirus. J. Virol. 86, 11138-11150 (2012).

39. Loo, T., Patchett, M. L., Norris, G. E. \& Lott, J. S. Using secretion to solve a solubility problem: high-yield expression in Escherichia coli and purification of the bacterial glycoamidase PNGase F. Protein Expr. Purif. 24, 90-98 (2002). 
662

663

664

665

666

667

668

669

670

671

672

673

674

675

676

677

678

679

680

681

682

683

684

685

686

687

688

689

690

691

692

693

40. Geissner, A. et al. Microbe-focused glycan array screening platform. Proc. Natl. Acad. Sci. U.S.A. 116, 1958-1967 (2019).

41. de Paz, J. L., Noti, C. \& Seeberger, P. H. Microarrays of synthetic heparin oligosaccharides. J. Am. Chem. Soc. 128, 2766-2767 (2006).

42. Noti, C., de Paz, J. L., Polito, L. \& Seeberger, P. H. Preparation and use of microarrays containing synthetic heparin oligosaccharides for the rapid analysis of heparin-protein interactions. Chemistry 12, 8664-8686 (2006).

43. Wu, X., Ling, C.-C. \& Bundle, D. R. A new homobifunctional p-nitro phenyl ester coupling reagent for the preparation of neoglycoproteins. Org. Lett. 6, 4407-4410 (2004).

44. Schindelin, J. et al. Fiji: An open-source platform for biological-image analysis. Nat. Methods 9, 676-682 (2012).

45. Arganda-Carreras, I. et al. Trainable Weka Segmentation: a machine learning tool for microscopy pixel classification. Bioinformatics 33, 2424-2426 (2017).

46. Zheng, S. Q. et al. MotionCor2: anisotropic correction of beam-induced motion for improved cryo-electron microscopy. Nat. Methods 14, 331-332 (2017).

47. Penczek, P. A. et al. CTER-rapid estimation of CTF parameters with error assessment. Ultramicroscopy 140, 9-19 (2014).

48. Yang, Z., Fang, J., Chittuluru, J., Asturias, F. J. \& Penczek, P. A. Iterative stable alignment and clustering of 2D transmission electron microscope images. Structure 20, 237-247 (2012).

49. Trott, O. \& Olson, A. J. AutoDock Vina: improving the speed and accuracy of docking with a new scoring function, efficient optimization, and multithreading. J Comput Chem 31, 455-461 (2010).

50. Anandakrishnan, R., Aguilar, B. \& Onufriev, A. V. H++ 3.0: automating pK prediction and the preparation of biomolecular structures for atomistic molecular modeling and simulations. Nucleic Acids Res. 40, W537-41 (2012).

51. Moriarty, N. W., Grosse-Kunstleve, R. W. \& Adams, P. D. electronic Ligand Builder and Optimization Workbench (eLBOW): a tool for ligand coordinate and restraint generation. Acta Crystallogr. D Biol. Crystallogr. 65, 1074-1080 (2009). 
bioRxiv preprint doi: https://doi.org/10.1101/857730; this version posted November 29, 2019. The copyright holder for this preprint (which was not certified by peer review) is the author/funder, who has granted bioRxiv a license to display the preprint in perpetuity. It is made available under aCC-BY-NC-ND 4.0 International license.

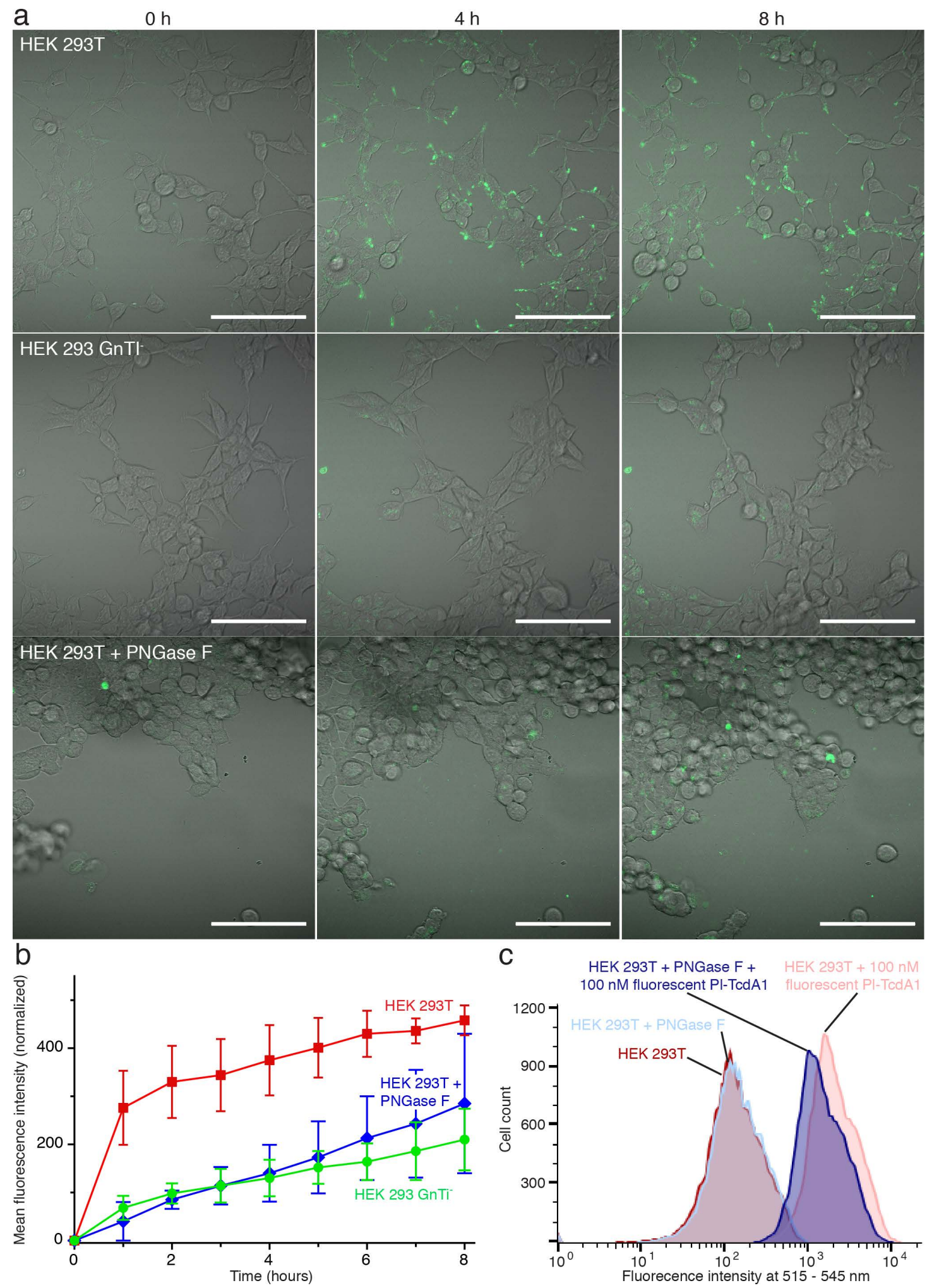

Figure 1: The presence of complex glycans on target cells enhances binding of Pl-

697 TedA1 a: Time course confocal imaging demonstrates that wild type HEK 293T cells 698 bind Pl-TcdA1 (AlexaFluor488 labelled, green) much more readily than their 


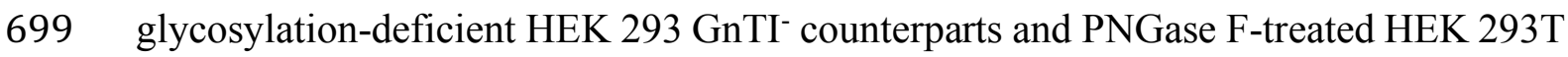

700 cells. Scale bar, $100 \mu \mathrm{m}$; fluorescence channels are equally thresholded. b:

701 Quantification of AlexaFluor488 labelled P1-TcdA1 binding to wild type HEK 293T,

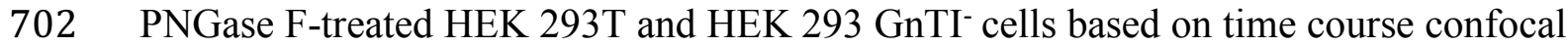

703 microscopy data. Three biological replicates for each cell type were analyzed; error bars

704 represent standard deviation. c: Flow cytometry of HEK 293T exposed to

705 AlexaFluor488 labelled P1-TcdA1 after deglycosylation of cell surface by PNGase F.

706 Histograms of PNGase F-treated and untreated cells, both with and without $100 \mathrm{nM} \mathrm{Pl-}$

707 TcdA1 are shown in comparison. The gating strategy and cell numbers are shown in

708 Supplementary data file 1. 

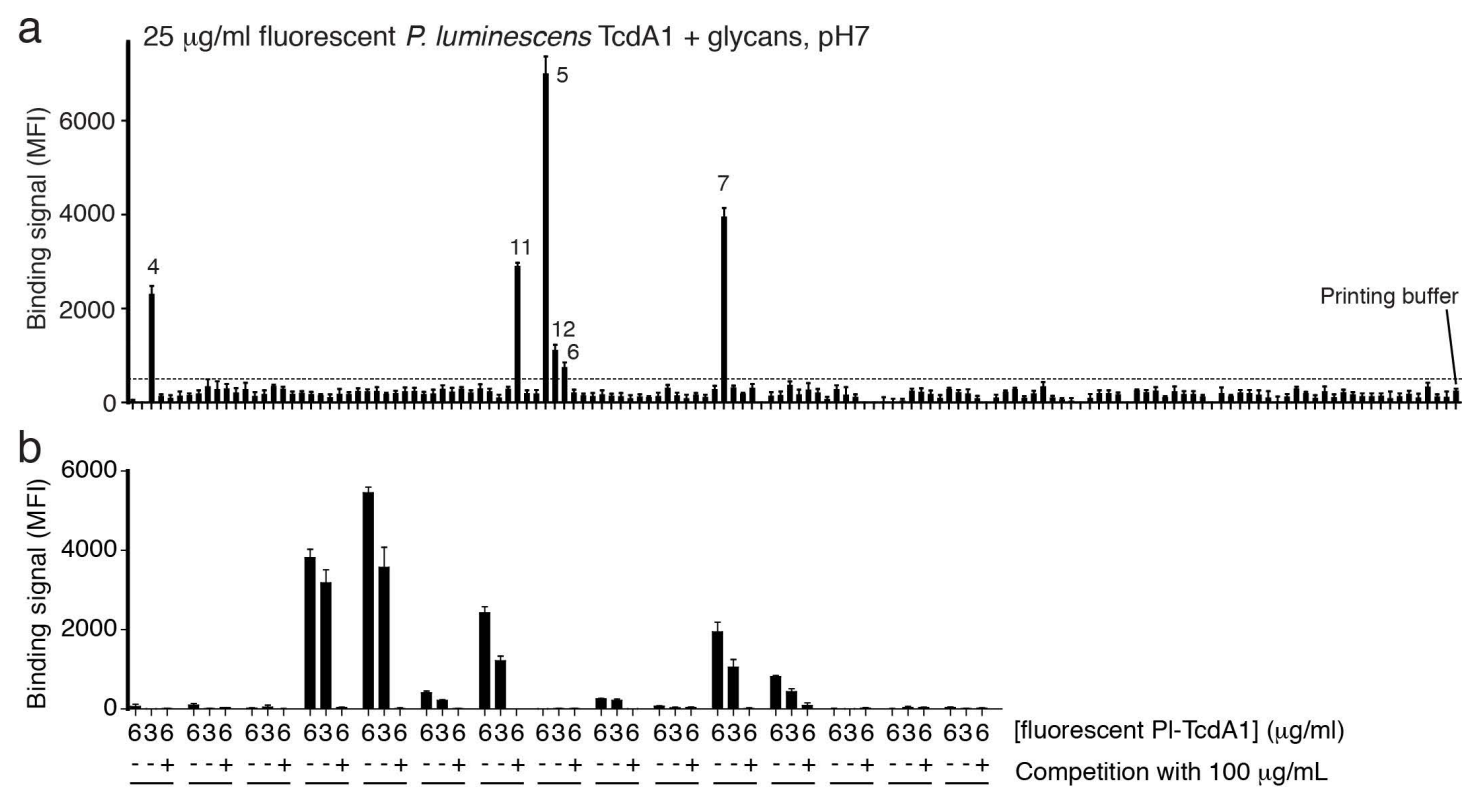

C No Binding
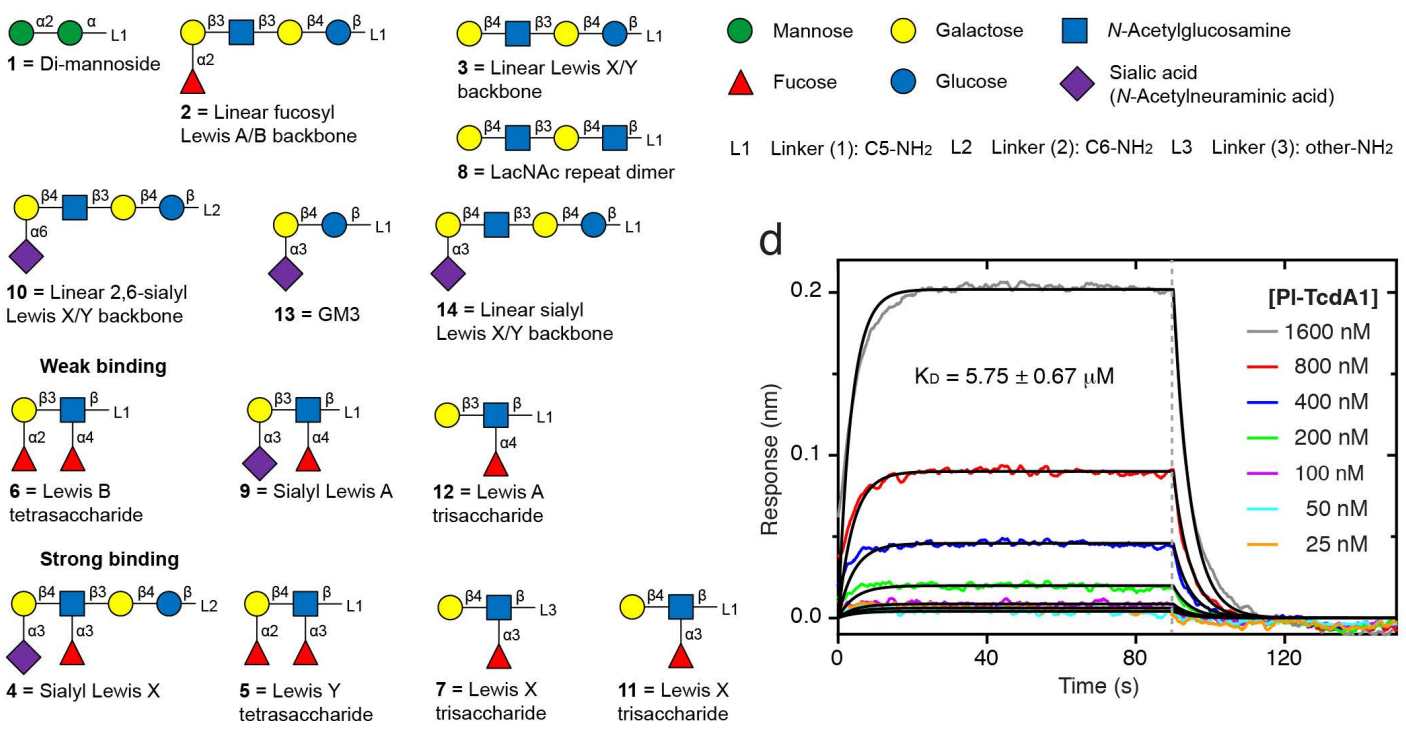

710 Figure 2: Interaction of Pl-TcdA1 with various Lewis antigens. a: Glycan

711 microarray showing the interaction of fluorescently labeled Pl-TcdA1 (fl-TcdA1) with

712 various glycans. Binding signals are shown as local background-subtracted mean

713 fluorescence intensity (MFI) values to 141 synthetic glycans. MFI values are indicated

714 as bars (mean \pm standard deviation). An arbitrary threshold of MFI=500 is indicated as

715 dashed line. b: Focused microarray with selected glycans from (a). 6 or $3 \mu \mathrm{g} / \mathrm{mL}$ of fl-

716 TcdA1 were applied to 14 different glycans (indicated below the bar diagrams, spotted 717 at $0.1 \mathrm{mM}$ ) in the absence or presence of an excess of unlabeled P1-TcdA1. c: Schematic 
718 representation of glycans used on the focused microarray, grouped by binding of Pl-

719 TcdA1 (no binding, weak binding and strong binding). The individual monosaccharide

720 moieties are shown on the top right. d: BLI sensorgrams of TcdA1 interacting with

721 immobilized BSA-Lewis X. TcA pentamer concentrations were $25-1600 \mathrm{nM}$. A

722 global fit according to a 1:1 binding model was applied (black curves), resulting in a

$723 \mathrm{~K}_{\mathrm{D}}$ of $5.75 \pm 0.67 \mu \mathrm{M}, \mathrm{k}_{\text {on }}$ of $3.81 \pm 0.44 \times 10^{4} \mathrm{M}^{-1} \mathrm{~s}^{-1}$, and $\mathrm{k}_{\text {off }}$ of $2.19 \pm 0.04 \times 10^{-1} \mathrm{~s}^{-1}$.

724 Association and dissociation phases are separated by a grey dotted line. 


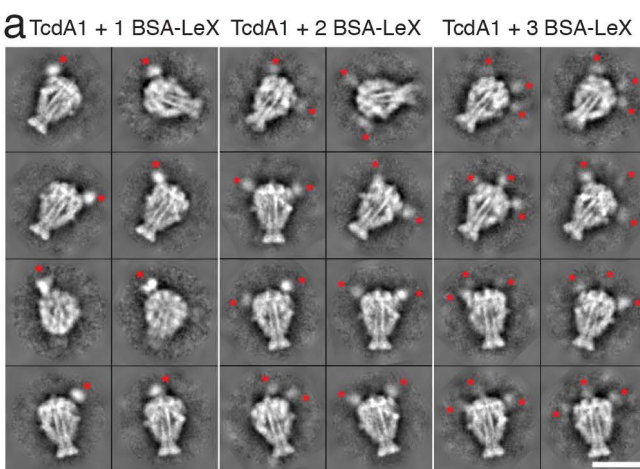

50427 particles, $58 \% 30754$ particles, $36 \% \quad 5452$ particles, $6 \%$
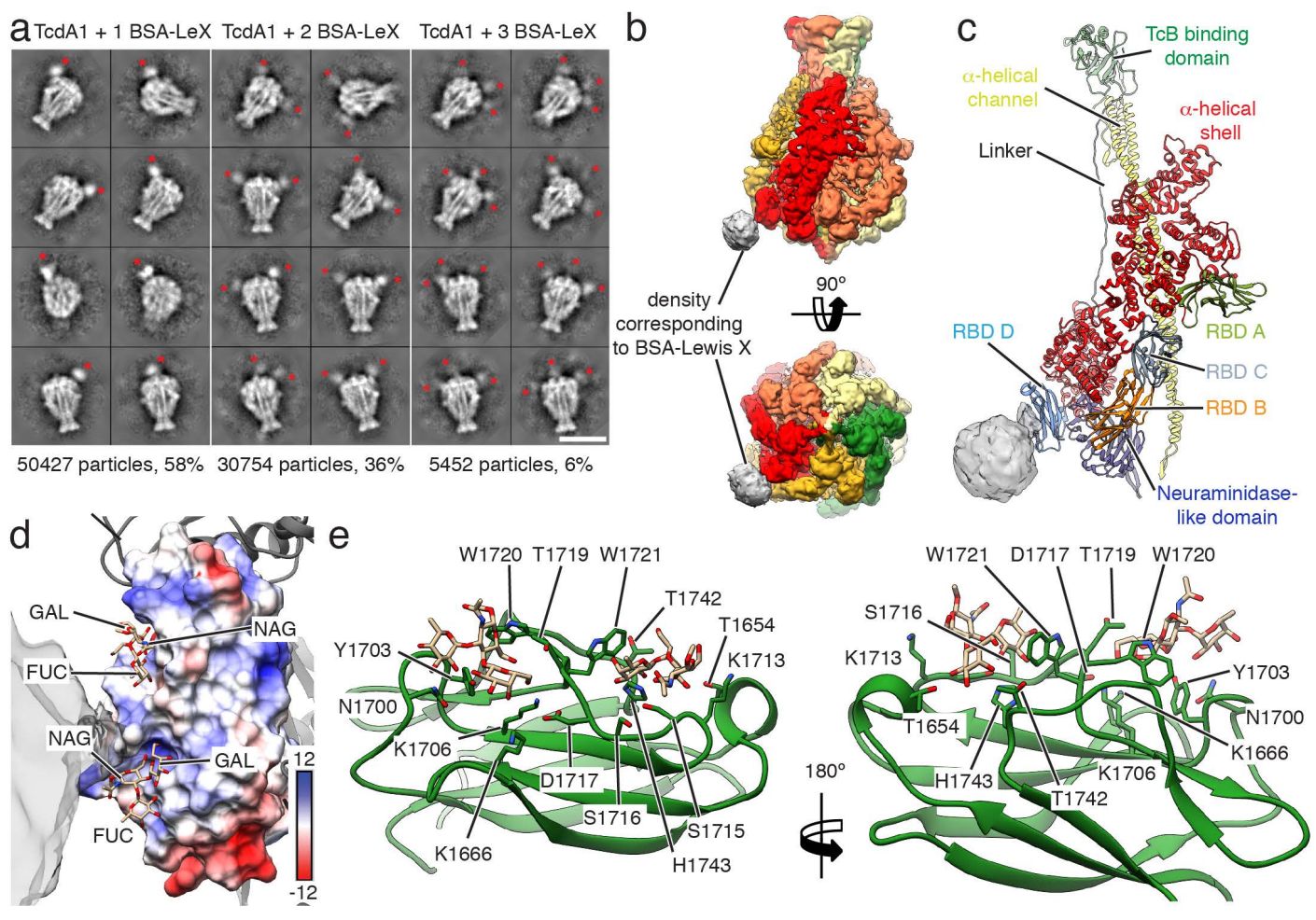

727 Figure 3: Structure of PI-TcdA1 with BSA-Lewis X. a: Representative reference-free

2D class averages of cryo-EM images of Pl-TcdA1 with crosslinked BSA-Lewis X

729 obtained by ISAC and resampled to the original pixel size. Scale bar, $20 \mathrm{~nm}$. b: Cryo-

730 EM map of Pl-TcdA1 with BSA-Lewis X. The protomers are colored individually.

731 Density corresponding to BSA-Lewis X (gray) is shown at lower binarization threshold.

732 C: Model of one protomer of P1-TcdA1 together with the cryo-EM density of BSA-

733 Lewis X (gray) at low binarization threshold. The domains of P1-TcdA1 are colored

734 individually. BSA-Lewis $\mathrm{X}$ is attached to RBD D. d: Surface representation of RBD-

$735 \mathrm{D}$, colored according to the Coulomb potential $\left(\mathrm{kcal} \mathrm{mol}^{-1} \mathrm{e}^{-1}\right)$ at $\mathrm{pH}$ 7.0. Two docked

736 conformations of Lewis $\mathrm{X}$ are shown as stick representations. The docking score is -4.5

$737 \mathrm{kcal} / \mathrm{mol}$ for both conformations. The cryo-EM density map corresponding to BSA-

738 Lewis $\mathrm{X}$ is transparent gray. e: Detailed view of RBD-D (green) with two docked

739 Lewis X molecules. Side chains that contact the docked molecules are highlighted. 


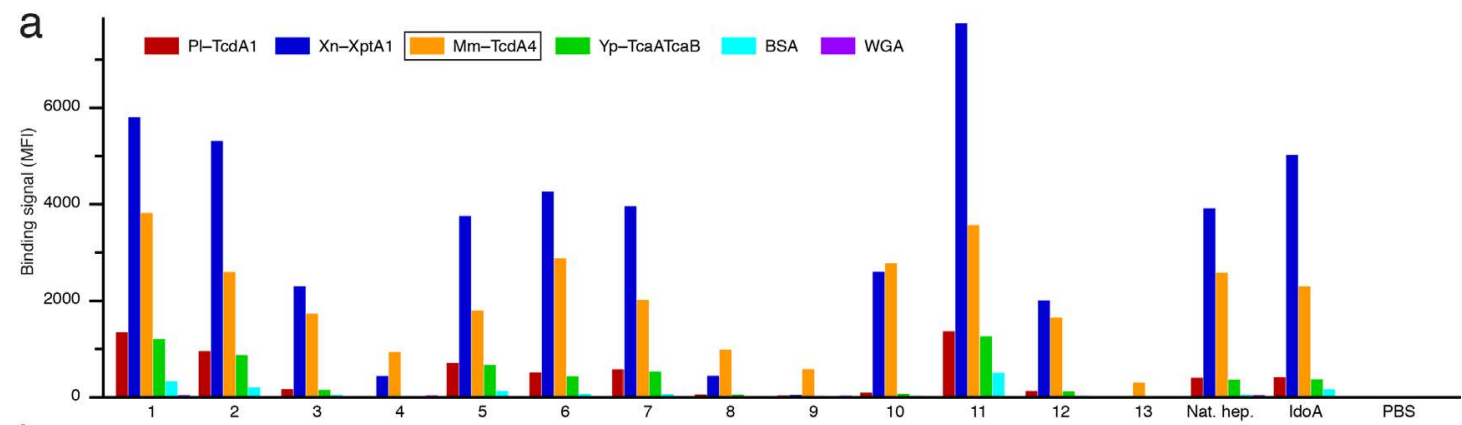

b
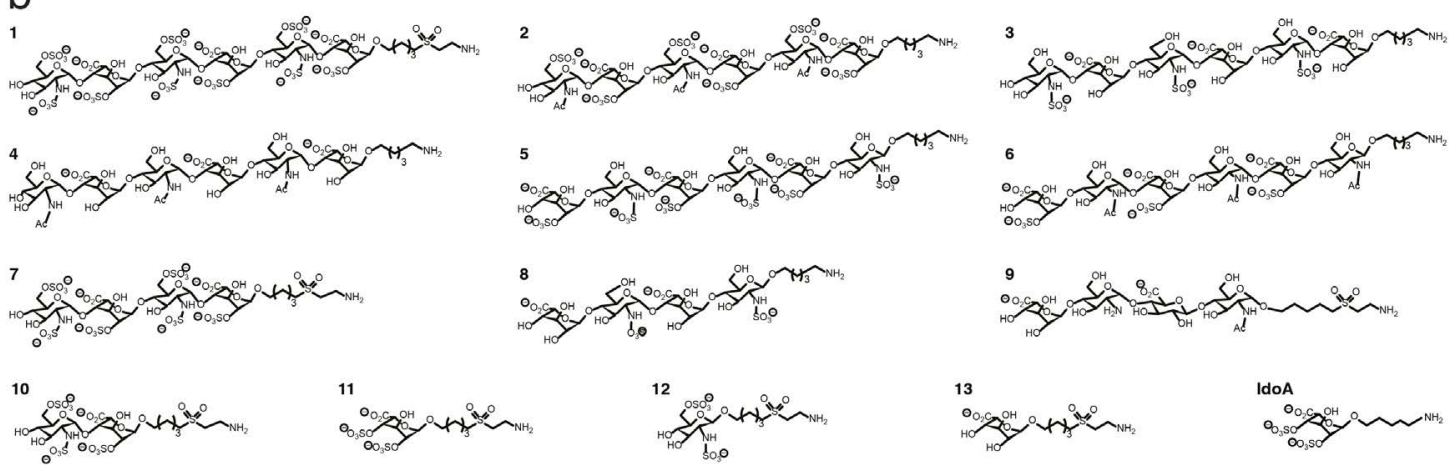

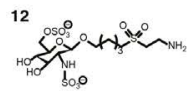

IdoA
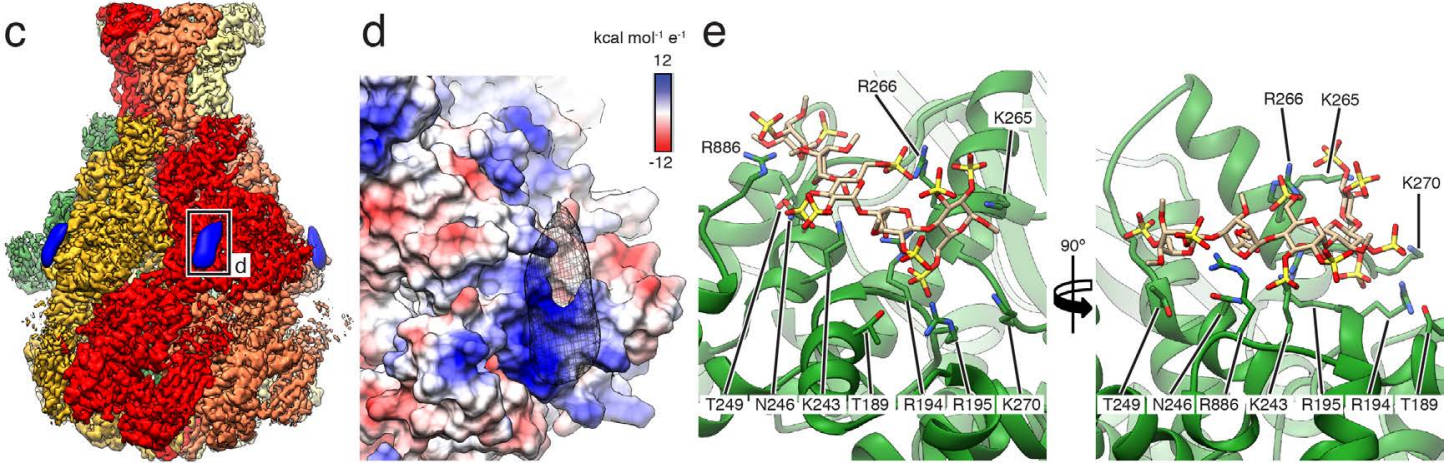

Figure 4: Interaction of TcAs with various heparin oligosaccharides and structure

of Mm-TedA4 in complex with heparin. a: Glycan microarray showing the

interaction of the indicated TcAs $(0.25 \mu \mathrm{g} / \mathrm{mL})$ with selected heparin oligosaccharides,

744 the natural heparin mixture from porcine intestinal mucosa (Nat. hep.), and the heparin

745 analogue IdoA-2,4-disulfate(a)linker (IdoA). As controls

746 bovine serum albumin (BSA) and wheat germ agglutinin (WGA) were used. As an

747 additional negative control phosphate-buffered saline (PBS) was spotted on the array.

748 The full heparin microarray is shown in Supplementary Figure 5a. b: Structures of

749 heparins 1-13 and IdoA. The numbers correspond to (a). c: Cryo-EM structure of Mm-

750 TcdA4 (highlighted in (a)) in complex with natural heparin. The protomers of Mm- 
751 TcdA4 are colored individually. Additional density not corresponding to the toxin is

752 filtered to $15 \AA$ and shown in blue. $d$ : Surface representation of the heparin binding site

753 of the shell domain of Mm-TcdA4, colored according to the Coulomb potential (kcal

$\left.754 \mathrm{~mol}^{-1} \mathrm{e}^{-1}\right)$ at $\mathrm{pH}$ 7.0. The additional density corresponding to heparin is shown in black

755 mesh representation. e: The interface region of the Mm-TcdA4 shell domain (green)

756 with side chains that contact a docked heparin pentasaccharide (sand colored). The

757 docking score is $-6.2 \mathrm{kcal} / \mathrm{mol}$. All residues belong to the $\alpha$-helical part of the shell. 


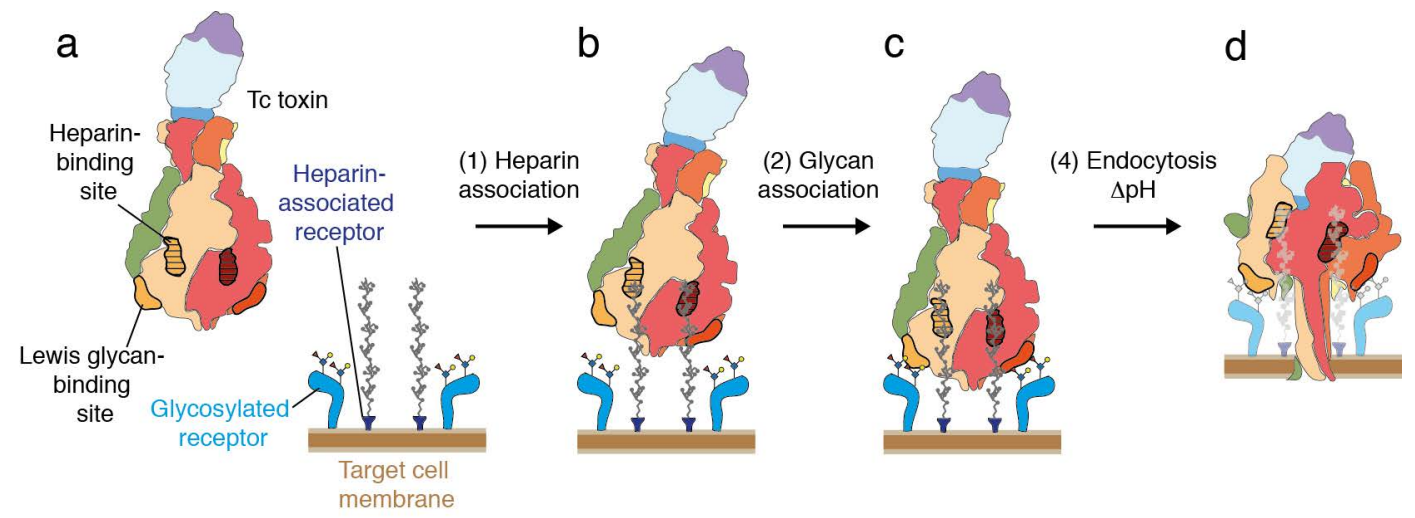

759 Figure 5: Model of the intoxication mechanism of Tc. a: Tc toxin and target cells

760 with multiple glycosylated and heparin-associated receptors. The binding sites for

761 heparin and Lewis antigens are indicted on two protomers. b: Tc toxin associates to

762 heparin-associated receptors on target cells. c: In a second association reaction, Tc toxin

763 binds to additional glycosylated receptors, resulting in a tighter toxin-cell-complex. d:

764 Upon endocytosis, the shift of $\mathrm{pH}$ to acidic values induces prepore-to-pore transition

765 and membrane permeation of the Tc toxin. 


\section{Supplementary Figures}

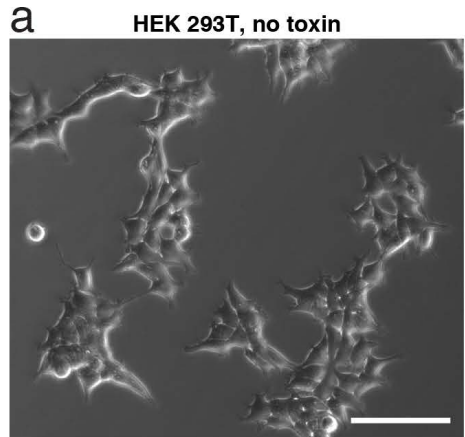

HEK $293 \mathrm{GnTI}^{-}$, no toxin

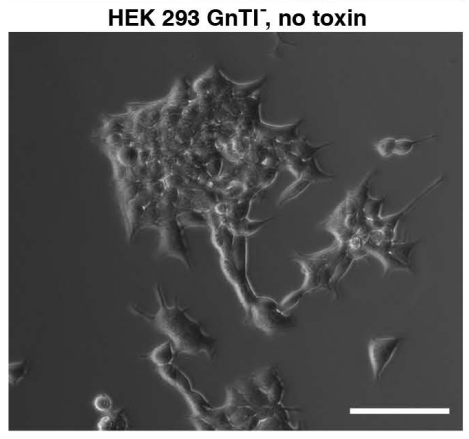

b

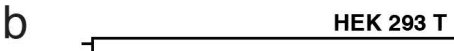

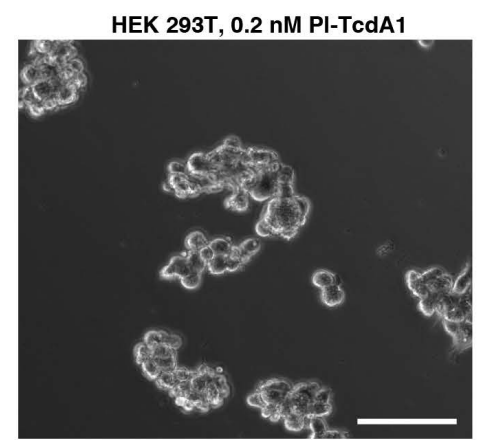

HEK 293 GnTI; 0.2 nM PI-TcdA1

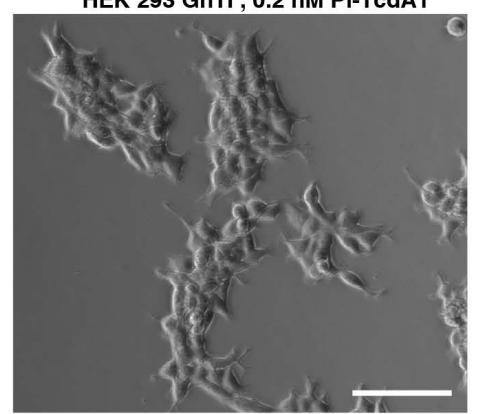

HEK 293T, 2 nM PI-TcdA1

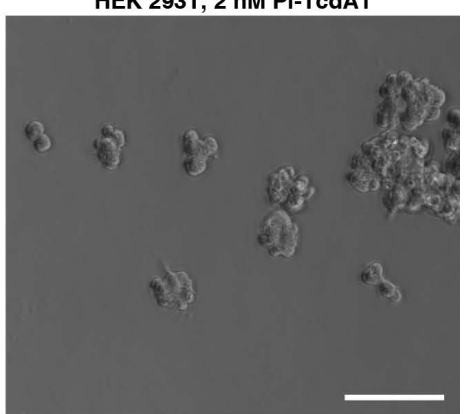

HEK 293 GnTI; 2 nM PI-TcdA1

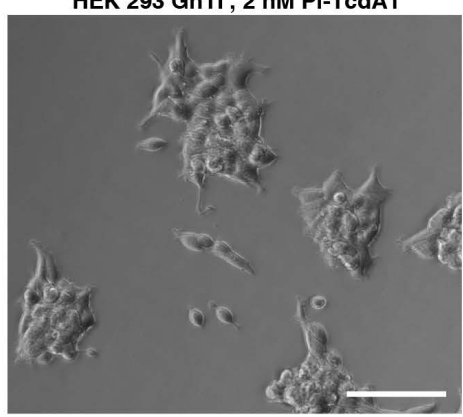

HEK $293 \mathrm{GnTI}^{-}$
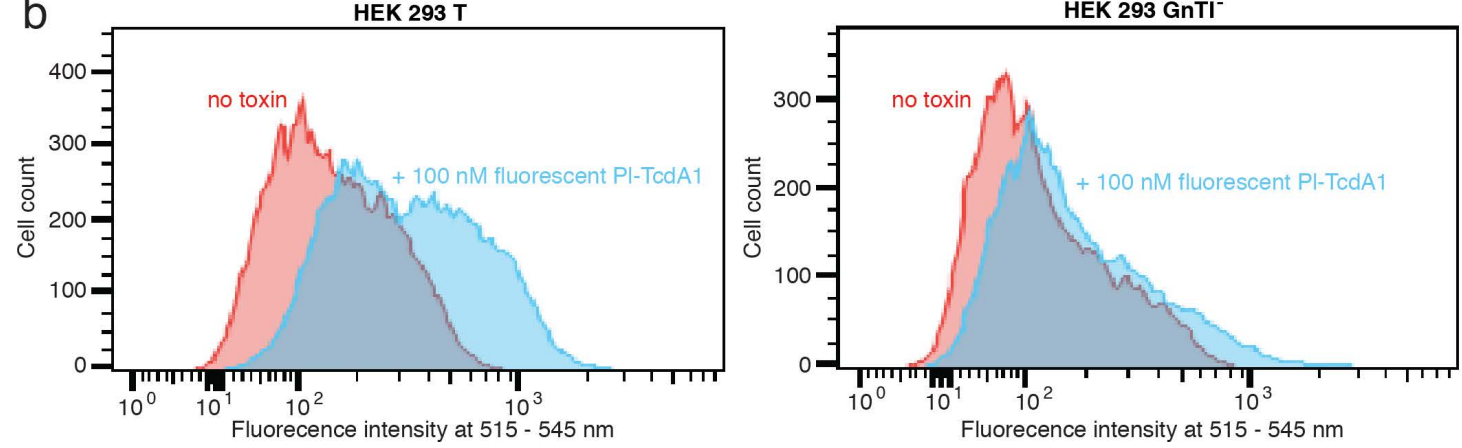

768 Supplementary Figure 1: Toxicity and binding of Tc to HEK 293 T and HEK 293

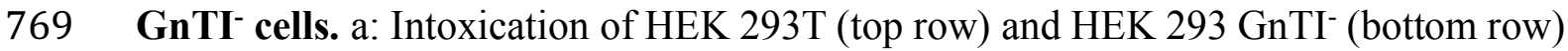

770 with Tc holotoxin (P1-TcdA1 with Pl-TcdB2-TccC3). Images show cells $16 \mathrm{~h}$ after

771 intoxication. Intoxicated cells round up and detach from the surface. Experiments were

772 performed in triplicates with qualitatively identical results. Scale bars, $100 \mu \mathrm{m}$. b: Flow

773 cytometry of HEK 293T (left) and HEK $293 \mathrm{GnTI}^{-}$(right) exposed to AlexaFluor488

774 labelled P1-TcdA1. Histograms of cells, both with and without $100 \mathrm{nM} \mathrm{P1-TcdA1}$ are

775 shown in comparison. 

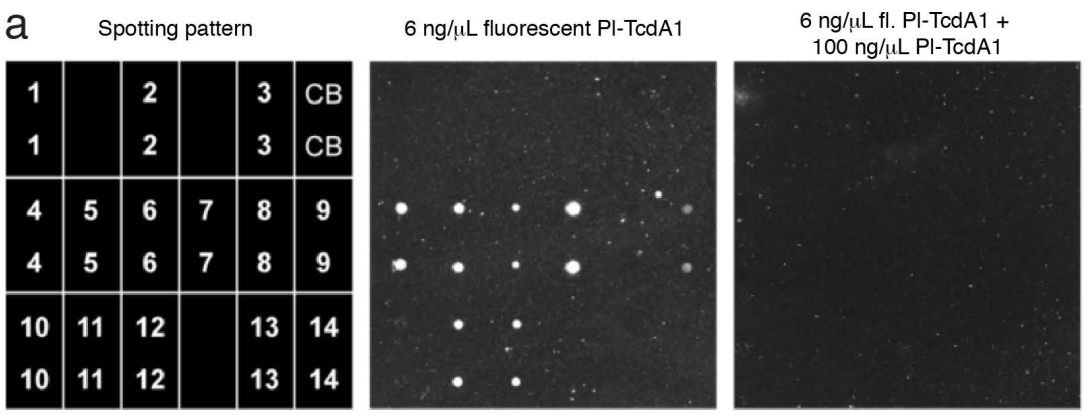

Control: $5 \mathrm{ng} / \mathrm{uL}$ Concanavalin A

$$
\begin{aligned}
& \text { No binding } \\
& \text { 1: Di-mannoside } \\
& \text { 2: Linear fucosyl LeA/B backbone } \\
& \text { 3: Linear LeX/Y backbone } \\
& \text { 8: LacNAc repeat dimer } \\
& \text { 10: Linear 2,6-sialyl LeX/Y backbone } \\
& \text { 13: GM } 3 \\
& \text { 14: Linear sialyl LeX/Y backbone }
\end{aligned}
$$

Weak binding Strong binding

$\begin{array}{ll}\text { 6: LeB tetrasaccharide } & \text { 4: Sialyl LeX }\end{array}$

$\begin{array}{ll}\text { 6: LeB tetrasaccharide } & \text { 4: Sialyl LeX } \\ \text { 9: Sialyl LeA } & \text { 5: LeY tetrasaccharide }\end{array}$

12: LeA trisaccharide $\quad$ 7: LeX trisaccharide

11: LeX trisaccharide
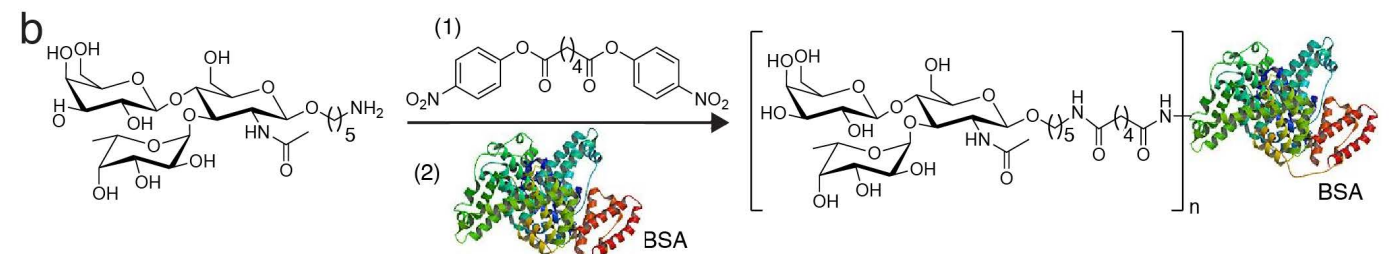

Reagents and conditions: (1): Di-para-nitrophenol adipate, DMSO/pyridine, $2 \mathrm{~h}, 25^{\circ} \mathrm{C}$; (2): $\mathrm{BSA}, \mathrm{Na}-\mathrm{Pi} \mathrm{pH} 8.0,24 \mathrm{~h}$

C MALDI-TOF MS
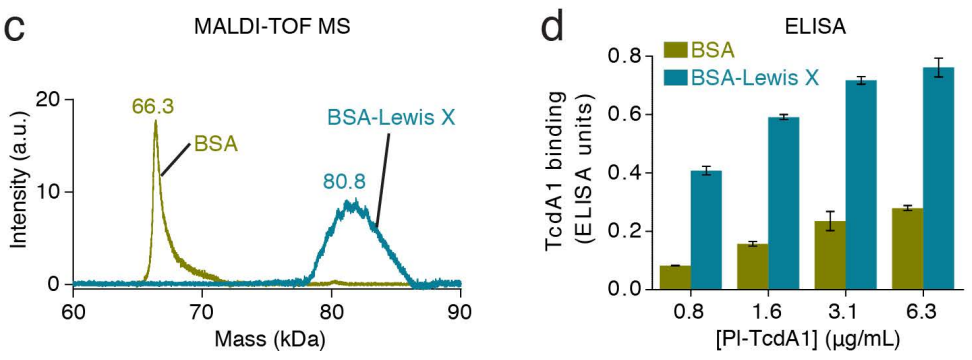

Supplementary Figure 2: Glycan microarray of PI-TcdA1 and preparation of

BSA-Lewis X. a: Spotting pattern of glycans on the chip surface in duplicates (left),

fluorescence readout after incubation with $6 \mathrm{ng} / \mu \mathrm{L}$ fluorescently labeled Pl-TcdA1 (fl-

TcdA1) alone (middle left) and together with a 17-fold excess of unlabeled P1-TcdA1

781 (middle right), and fluorescence readout after incubation with concanavalin A (right).

782 The glycans immobilized on the chip (structures are shown in Figure 2c) are shown

783 below the chip scheme and are grouped according to their interaction with Pl-TcdA1.

784 b: Reaction scheme showing the preparation of BSA-Lewis X. c: Mass spectrometry

785 (MALDI-TOF MS) of the obtained BSA-Lewis X glycoconjugate in comparison to

786 BSA. The average mass increase of $14.5 \mathrm{kDa}$ shows the immobilization of $\sim 20$ Lewis $\mathrm{X}$ 
bioRxiv preprint doi: https://doi.org/10.1101/857730; this version posted November 29, 2019. The copyright holder for this preprint (which was not certified by peer review) is the author/funder, who has granted bioRxiv a license to display the preprint in perpetuity. It is made available under aCC-BY-NC-ND 4.0 International license. of Pl-TcdA1 to BSA-Lewis X and weak binding to BSA. 

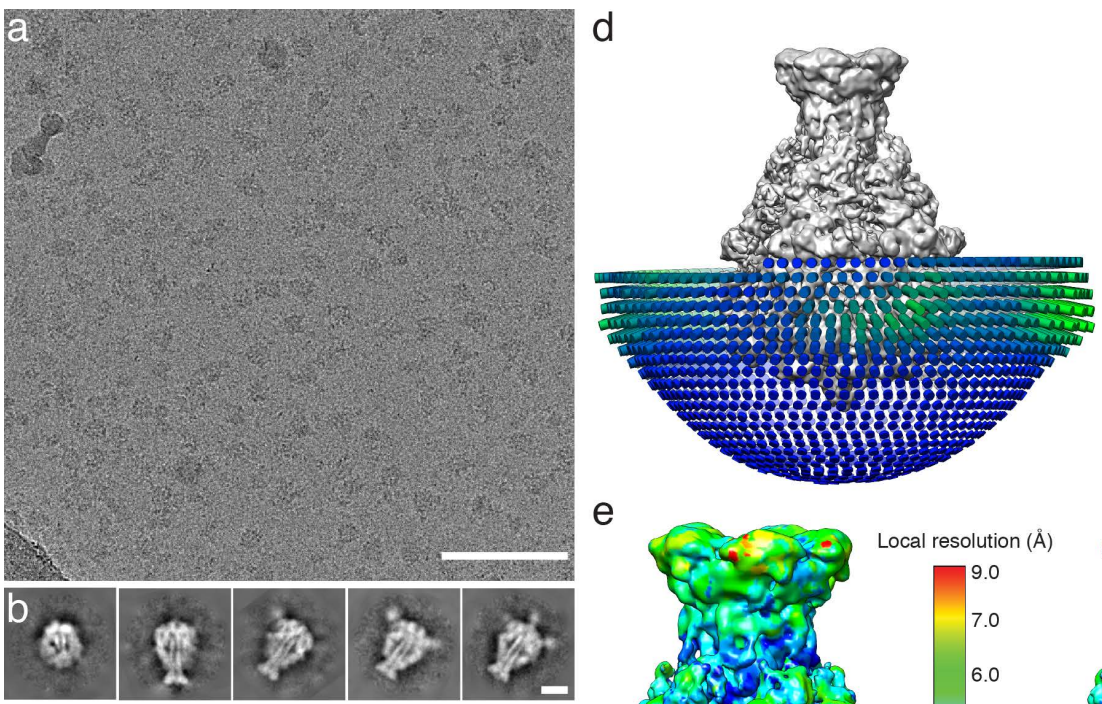

e Local resolution $(\AA)$

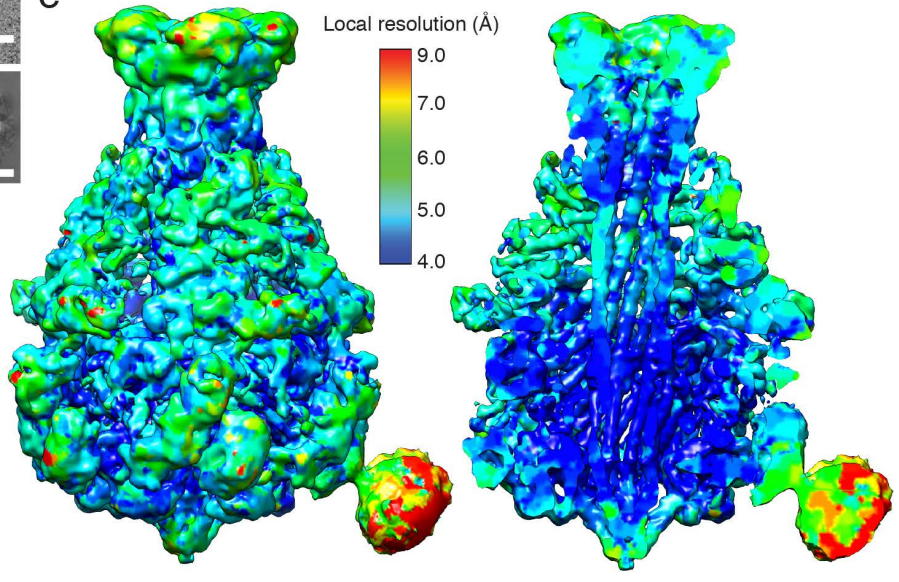

Supplementary Figure 3: Cryo-EM of Pl-TedA41 and crosslinked BSA-Lewis X.

a: Typical digital micrograph area of vitrified Pl-TcdA1-BSA-Lewis X complexes at a defocus of $2 \mu \mathrm{m}$ and a total dose of $100 \mathrm{e}^{-} \AA^{-2}$ acquired with a Falcon III direct electron detector. Scale bar, $100 \mathrm{~nm}$. b: Representative reference-free 2D class averages obtained by ISAC and subsequently resampled to the original pixel size, refined and sharpened, using the Beautifier tool implemented in the SPHIRE software package.

797 Scale bar, 10 nm. c: Fourier shell correlation (FSC) of the cryo-EM map (black curve).

798 The 0.143 FSC cut-off criterion indicates that the cryo-EM map has an average 799 resolution of $5.0 \AA$ A. d: Angular distribution for the final round of the refinement. Each 800 stick represents a projection view. Size and color of the stick is proportional to the 801 number of particles. e: Surface and cross-section of the cryo-EM density map colored 802 according to the local resolution. The map sections corresponding to the Pl-TcdA1 803 pentamer and BSA-Lewis $\mathrm{X}$ are shown at different binarization thresholds. 


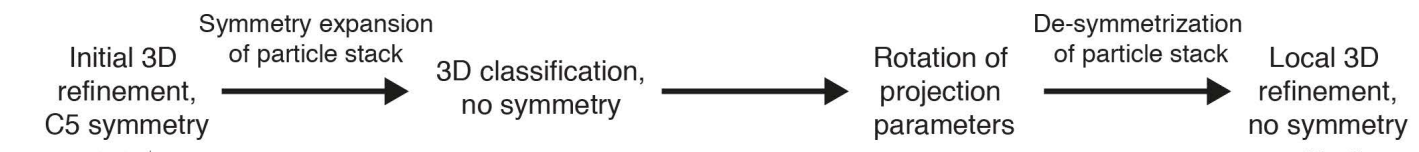

805 Supplementary Figure 4: Workflow of 3D classification and refinement for Pl-

806 TedA1-BSA-Lewis X. Initial 3D refinement with C5 symmetry resulted in weak

807 density for BSA-Lewis X (arrows) which binds sub-stoichiometrically (left panel).

808 Therefore, we performed symmetry expansion of the particle stack and 3D

809 classification after 3D refinement. The 3D classes were rotated in $72^{\circ}$ steps so that the

810 additional density corresponding to BSA-Lewis X was located in the same position and

811 the projection parameters adjusted. The stack was then de-symmetrized and a local 3D

812 refinement without symmetry was performed, resulting in a map with BSA-Lewis X

813 oriented at one interaction site of Pl-TcdA1 (right panel). The resolution of the final

$814 \operatorname{map}$ is $5 \AA$. 

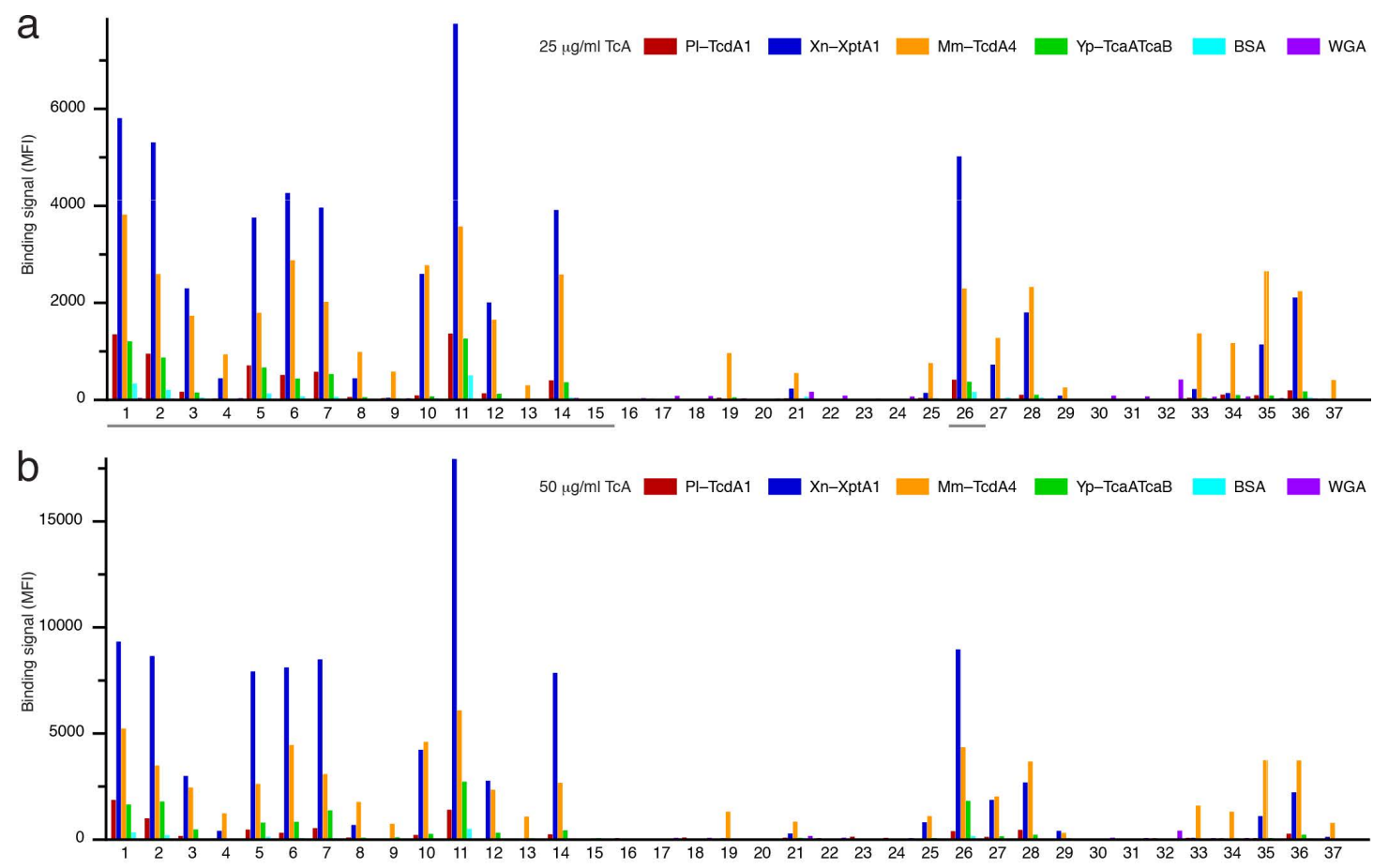

C M. morganii TcdA4 + porcine mucosa heparin

817 Supplementary Figure 5: Interaction of TcA with heparins. a,b: Glycan microarray

818 showing the interaction of Pl-TcdA1, Xn-XptA1, Mm-TcdA4, Yp-TcaA-TcaB with

819 various heparins and heparin-like glycans ${ }^{41,42}$. The protein concentration is $25 \mu \mathrm{g} / \mathrm{ml}$

820 (a) and $50 \mu \mathrm{g} / \mathrm{ml}$ (b), respectively. BSA and WGA were used as controls. At positions

82115 and 37, PBS was spotted on the array as negative control. The gray bars in (a)

822 indicate the molecules that are presented in Figure 4a,b. c: BLI sensorgrams of Mm-

823 TcdA4 $(8 \mathrm{nM}-500 \mathrm{nM})$ with immobilized biotinylated porcine intestinal mucosa

824 heparin. The black lines show a global fit according to a 1:1 binding model, resulting 
bioRxiv preprint doi: https://doi.org/10.1101/857730; this version posted November 29, 2019. The copyright holder for this preprint (which was not certified by peer review) is the author/funder, who has granted bioRxiv a license to display the preprint in perpetuity. It is made available under aCC-BY-NC-ND 4.0 International license.

825 in an apparent $\mathrm{K}_{\mathrm{D}}$ of $228 \pm 3 \mathrm{pM}, \mathrm{k}_{\text {on }}$ of $2.45 \pm 0.03 \times 10^{4} \mathrm{M}^{-1} \mathrm{~s}^{-1}$, and $\mathrm{k}_{\text {off }}$ of $4.49 \pm$ $8260.03 \times 10^{-4} \mathrm{~s}^{-1}$. 

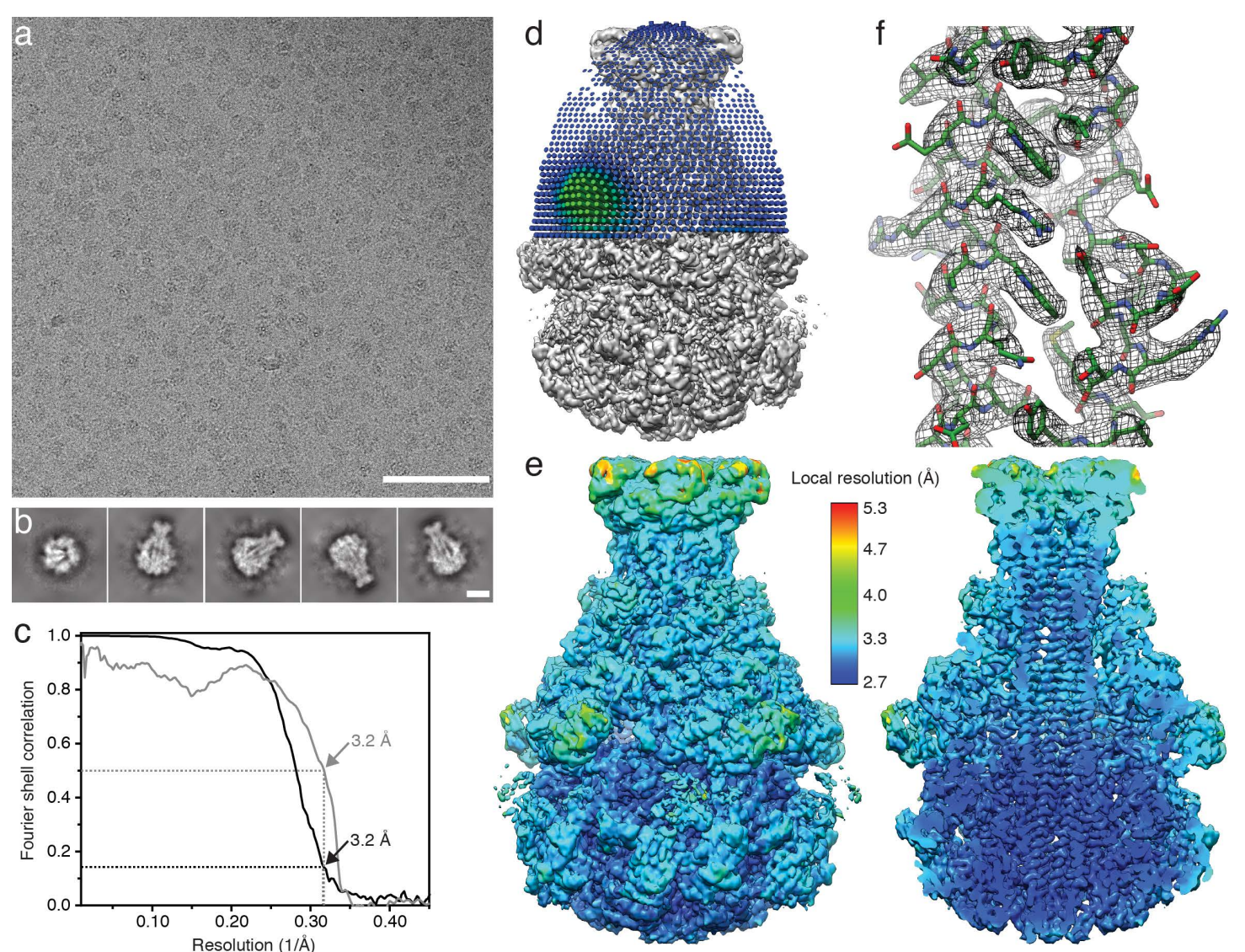

828 Supplementary Figure 6: Cryo-EM of Mm-TcdA4 in complex with heparin. a:

829 Typical digital micrograph area of vitrified TcdA4-heparin complexes at a defocus of

$8302 \mu \mathrm{m}$ and a total dose of $100 \mathrm{e}^{-} \AA^{-2}$ acquired with a Falcon III direct electron detector.

831 Scale bar, $100 \mathrm{~nm}$. b: Representative reference-free 2D class averages obtained by

832 ISAC and subsequently resampled to the original pixel size, refined and sharpened,

833 using the Beautifier tool implemented in the SPHIRE software package. Scale bar,

83410 nm. c: Fourier shell correlation (FSC) of the cryo-EM map (black curve). The 0.143

835 FSC cut-off criterion indicates that the cryo-EM map has an average resolution of $3.2 \AA$.

836 The gray curve shows the FSC curve between the final map versus the atomic model.

837 The 0.5 FSC cut-off criterion indicates a resolution of $3.2 \AA$. d: Angular distribution for

838 the final round of the refinement. Each stick represents a projection view. Size and color

839 of the stick is proportional to the number of particles. e: Surface and cross-section of

840 the cryo-EM density map colored according to the local resolution. f: Superimposition 
bioRxiv preprint doi: https://doi.org/10.1101/857730; this version posted November 29,2019 . The copyright holder for this preprint (which was not certified by peer review) is the author/funder, who has granted bioRxiv a license to display the preprint in perpetuity. It is made available under aCC-BY-NC-ND 4.0 International license.

841 of the cryo-EM density map and the model, shown for a representative area in the $\alpha$ -

842 helical channel. 

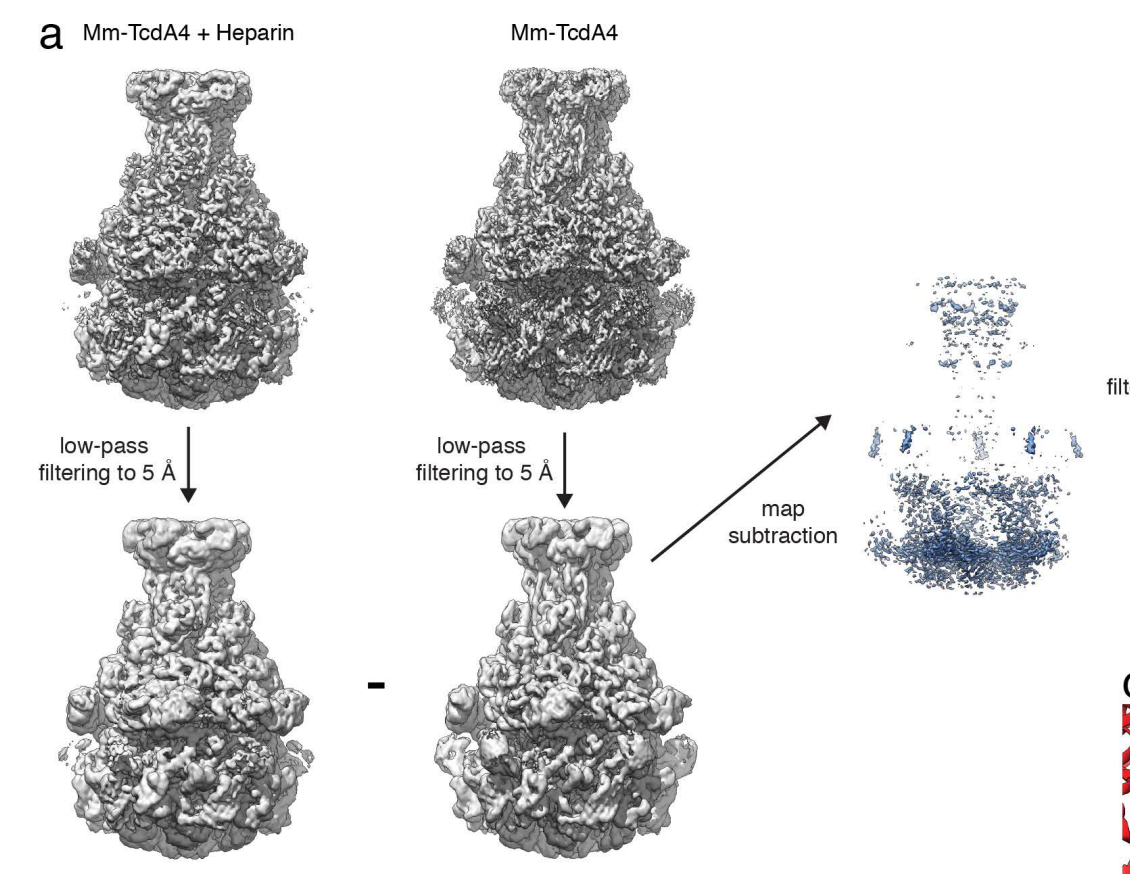

low-pass

filtering to $15 \AA$

b
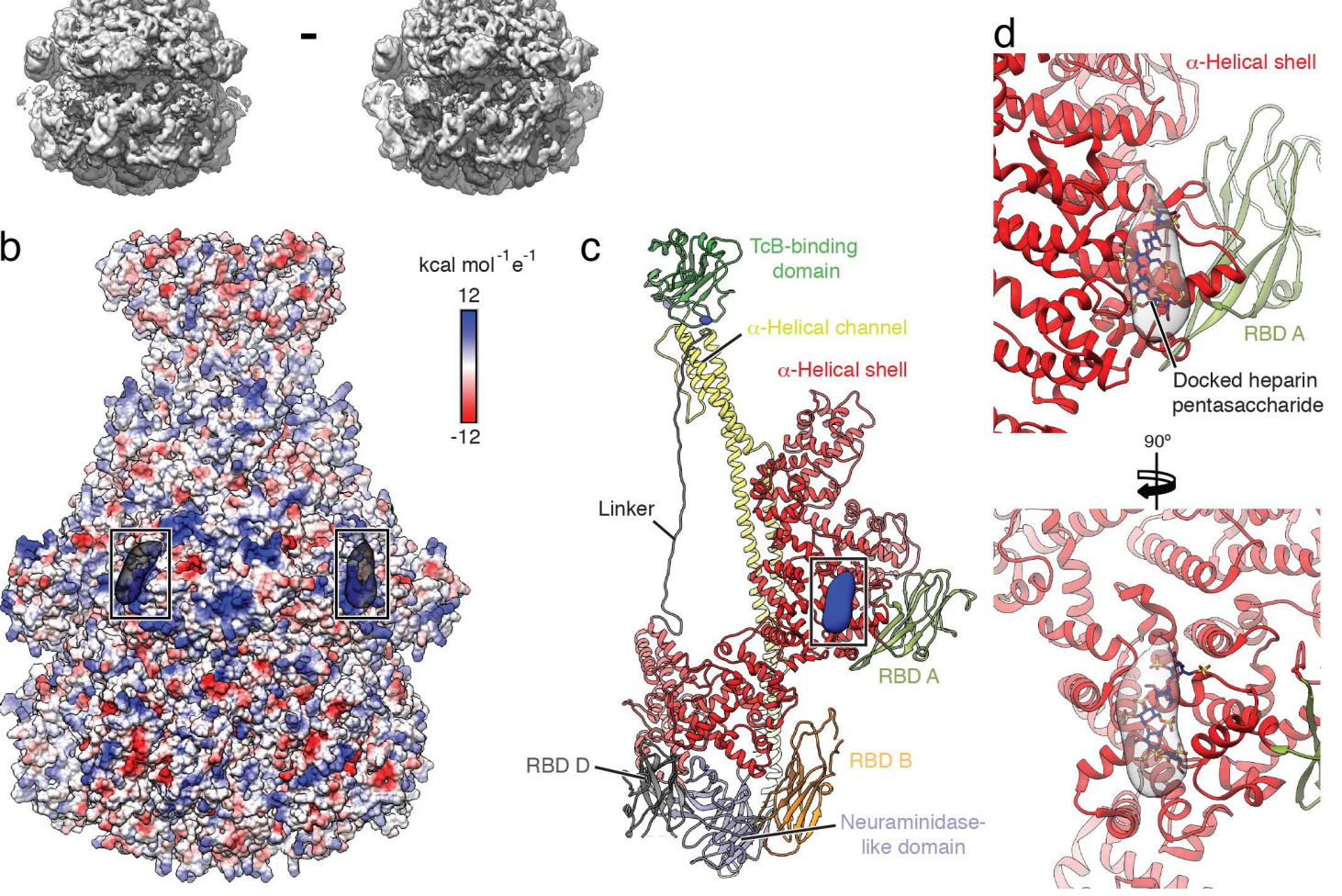

843

Supplementary Figure 7: Comparison of Mm-TedA4 without and with heparin. a:

845 Illustration of map subtraction to obtain the difference density map between Mm-

846 TcdA4 in the absence of heparin ${ }^{23}$ and Mm-TcdA4 in the presence of porcine intestinal

847 mucosa heparin. After lowpass filtering of both maps to $5 \AA$, the map of Mm-TcdA4 is

848 subtracted from the map of Mm-TcdA4 with heparin. The obtained difference density

849 map is filtered to $15 \AA$ resolution for illustrative purposes. b: Surface representation of

850 Mm-TcdA4, colored according to the Coulomb potential $\left(\mathrm{kcal} \mathrm{mol}^{-1} \mathrm{e}^{-1}\right)$ at $\mathrm{pH}$ 7.0. The

851 boxes indicate the obtained difference density map (transparent gray) on two protomers. 
852 c: Model of one Mm-TcdA4 protomer with difference density map (blue) obtained in

853 panel a. d: Illustration of the docked pentasaccharide (NTP, dark blue) on Mm-TcdA4.

854 The docking solution that resulted in the best match with the difference density

855 (transparent gray) is shown. 


\section{Supplementary Movie legends}

857

858 Supplementary Movie 1: Cryo-EM density map of Pl-TcdA1/BSA-Lewis X. The map

859 section corresponding to BSA-Lewis $\mathrm{X}$ is displayed at a lower binarization threshold.

860 A surface representation of RBD D and the docked BSA-Lewis X molecules are shown.

861

862 Supplementary Movie 2: Cryo-EM density map of Mm-TcdA4/heparin with the fitted

863 atomic model. The difference density of the cryo-EM maps of Mm-TcdA4/heparin and

864 Mm-TcdA4 is shown at the heparin binding site at the $\alpha$-helical shell. The docked

865 heparin is shown in the difference density.

866

867 
bioRxiv preprint doi: https://doi.org/10.1101/857730; this version posted November 29, 2019. The copyright holder for this preprint (which was not certified by peer review) is the author/funder, who has granted bioRxiv a license to display the preprint in perpetuity. It is made available under aCC-BY-NC-ND 4.0 International license.

Supplementary Tables

869

870 Supplementary Table 1: Cryo-EM data collection, refinement and validation statistics

871 for Mm-TcdA4/Heparin and Pl-TcdA1/BSA-Lewis X.

\begin{tabular}{|c|c|c|}
\hline & $\begin{array}{l}\text { Mm- } \\
\text { TcdA4/Heparin }\end{array}$ & $\begin{array}{l}\text { Pl-TcdA1/BSA- } \\
\text { Lewis X }\end{array}$ \\
\hline \multicolumn{3}{|l|}{ Data collection and processing } \\
\hline Camera & Falcon III & Falcon III \\
\hline Magnification & 59,000 & 59,000 \\
\hline Voltage $(\mathrm{kV})$ & 300 & 300 \\
\hline Exposure time (s) & 1.5 & 1.5 \\
\hline Total electron exposure $\left(\mathrm{e}-/ \AA^{2}\right)$ & 100 & 100 \\
\hline Defocus range $(\mu \mathrm{m})$ & $1.2-2.2$ & $1.0-2.5$ \\
\hline Pixel size $(\AA)$ & 1.11 & 1.11 \\
\hline Symmetry imposed & C5 & $\mathrm{C} 5+\mathrm{C} 1$ \\
\hline Initial particle images (no.) & 477,602 & 711,872 \\
\hline Final particle images (no.) & 182,506 & 199,038 \\
\hline $\begin{array}{l}\text { Map resolution }(\AA) \\
\text { FSC threshold }\end{array}$ & $\begin{array}{l}3.2 \\
0.143\end{array}$ & $\begin{array}{l}5.0 \\
0.143\end{array}$ \\
\hline Map sharpening $B$ factor $\left(\AA^{2}\right)$ & -127.06 & -80.00 \\
\hline \multicolumn{3}{|l|}{ Refinement } \\
\hline Initial model used (PDB code) & 6RW9 & \\
\hline $\begin{array}{l}\text { Model resolution }(\AA) \\
\text { FSC threshold }\end{array}$ & $\begin{array}{l}3.2 \\
0.5\end{array}$ & \\
\hline $\begin{array}{l}\text { Model composition } \\
\text { Non-hydrogen atoms } \\
\text { Protein residues } \\
\text { Ligands }\end{array}$ & $\begin{array}{l}88,700 \\
11,425\end{array}$ & \\
\hline $\begin{array}{l}\text { Mean B factors }\left(\AA^{2}\right) \\
\text { Protein }\end{array}$ & 55.78 & \\
\hline $\begin{array}{l}\text { R.m.s. deviations } \\
\text { Bond lengths }(\AA) \\
\text { Bond angles }\left({ }^{\circ}\right) \\
\end{array}$ & $\begin{array}{l}0.011 \\
0.901 \\
\end{array}$ & \\
\hline $\begin{array}{l}\text { Validation } \\
\text { MolProbity score } \\
\text { EMRinger score } \\
\text { Clashscore } \\
\text { Rotamer outliers }(\%) \\
\end{array}$ & $\begin{array}{l}2.46 \\
2.22 \\
13.89 \\
2.83 \\
\end{array}$ & \\
\hline $\begin{array}{l}\text { Ramachandran plot } \\
\text { Favored }(\%) \\
\text { Allowed (\%) } \\
\text { Disallowed (\%) }\end{array}$ & $\begin{array}{l}92.42 \\
7.40 \\
0.18\end{array}$ & \\
\hline
\end{tabular}

872

873 
bioRxiv preprint doi: https://doi.org/10.1101/857730; this version posted November 29, 2019. The copyright holder for this preprint (which was not certified by peer review) is the author/funder, who has granted bioRxiv a license to display the preprint in perpetuity. It is made available under aCC-BY-NC-ND 4.0 International license.

874 Supplementary Table 2: Overview of all glycans on the microarray in Figure 2a. For

875 additional information see reference no. 40.

\begin{tabular}{|c|c|c|c|}
\hline $\begin{array}{l}\text { Glycan } \\
\text { ID }\end{array}$ & Name & Structure & $\begin{array}{l}\text { Compound } \\
\text { no. Fig. 2a }\end{array}$ \\
\hline 5 & $\begin{array}{l}\text { Neu5Ac(a2-6)Gal(b1- } \\
\text { 4)GlcNAc(b1-3)Gal(b1- } \\
\text { 4)Glc(b1-1)aminohexanol }\end{array}$ & & \\
\hline 6 & $\begin{array}{l}\text { Neu5Ac(a2-3)Gal(b1- } \\
\text { 3)GlcNAc(b1-3)Gal(b1- } \\
\text { 4)Glc(b1-1)aminohexanol }\end{array}$ & & \\
\hline 7 & $\begin{array}{l}\text { Fuc(a1-3)[Neu5Ac(a2- } \\
\text { 3)Gal(b1-4)]GlcNAc(b1- } \\
\text { 3)Gal(b1-4)Glc(b1- } \\
\text { 1)aminohexanol }\end{array}$ & & 4 \\
\hline 8 & $\begin{array}{l}\text { Neu5Ac(a2-6)Gal(b1- } \\
\text { 4)Glc(b1-1)aminohexanol }\end{array}$ & & \\
\hline 9 & $\begin{array}{l}\text { Neu5Ac(a2-3)Gal(b1- } \\
\text { 4)Glc(b1-1)aminohexanol }\end{array}$ & & \\
\hline 10 & $\begin{array}{l}\text { Neu5Ac(a2-6)Gal(b1- } \\
\text { 4)GlcNAc-6-sulfate(b1- } \\
\text { 1)aminohexanol }\end{array}$ & & \\
\hline 11 & $\begin{array}{l}\text { Gal(b1-4)Glc(b1- } \\
\text { 1)aminohexanol }\end{array}$ & & \\
\hline 12 & $\begin{array}{l}\text { Gal(b1-4)GlcNAc-6- } \\
\text { sulfate(b1-1)aminohexanol }\end{array}$ & & \\
\hline 69 & $\begin{array}{l}\text { D-Araf(a1-5)D-Araf(a1- } \\
\text { 1)aminopentanol }\end{array}$ & & \\
\hline 70 & $\begin{array}{l}\text { D-Araf(a1-5)D-Araf(a1- } \\
\text { 3)[D-Araf(a1-5)D-Araf(a1- } \\
\text { 5)]D-Araf(a1-5)D-Araf(a1- } \\
\text { 1)aminopentanol }\end{array}$ & & \\
\hline 71 & $\begin{array}{l}\text { D-Araf(a1-3)[D-Araf(a1- } \\
\text { 5)]D-Araf(a1- } \\
\text { 1)aminopentanol }\end{array}$ & & \\
\hline 72 & $\begin{array}{l}\text { D-Araf(a1-5)D-Araf(a1- } \\
\text { 5)D-Araf(a1-5)D-Araf(a1- }\end{array}$ & 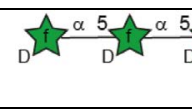 & \\
\hline
\end{tabular}




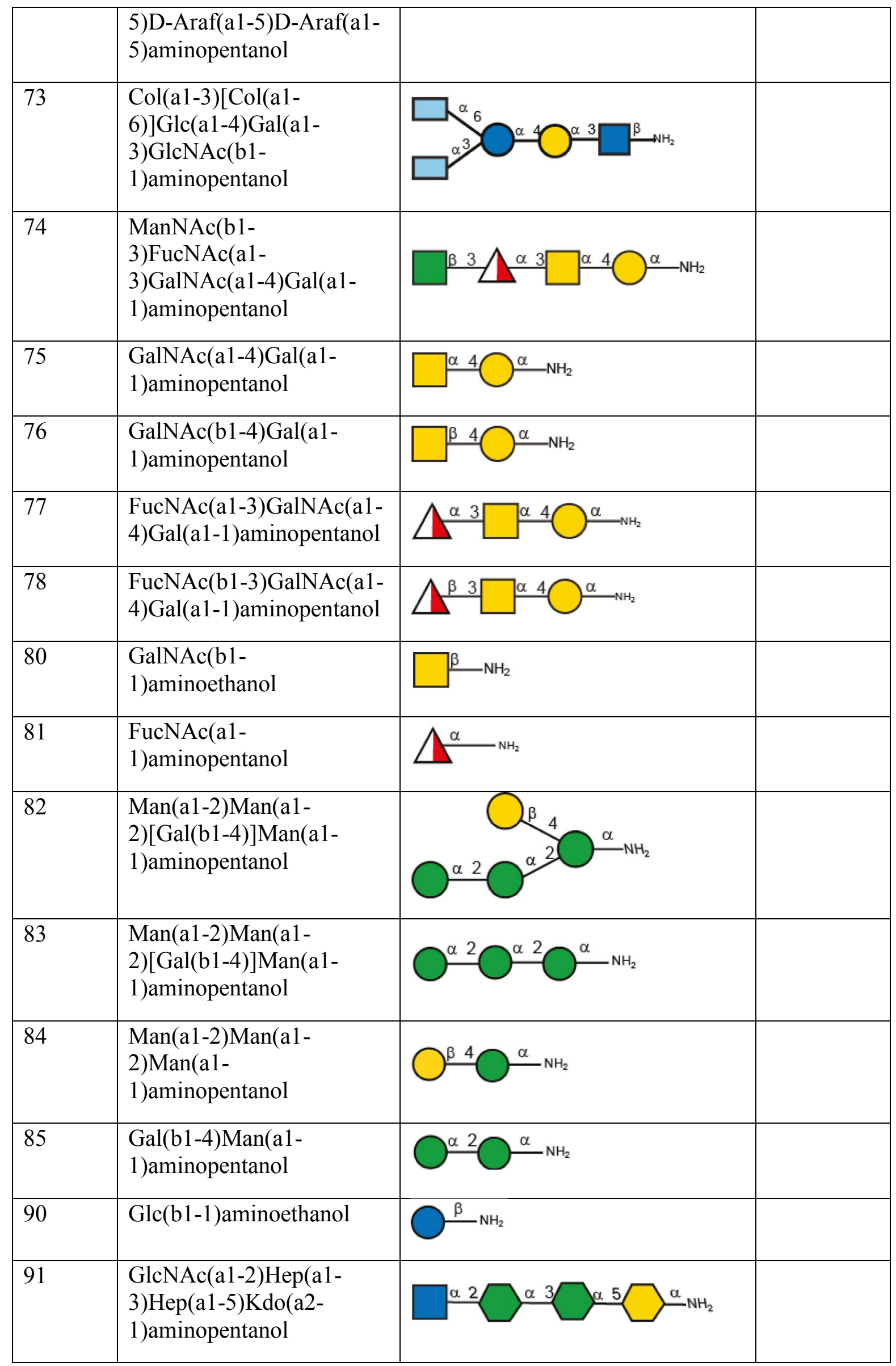




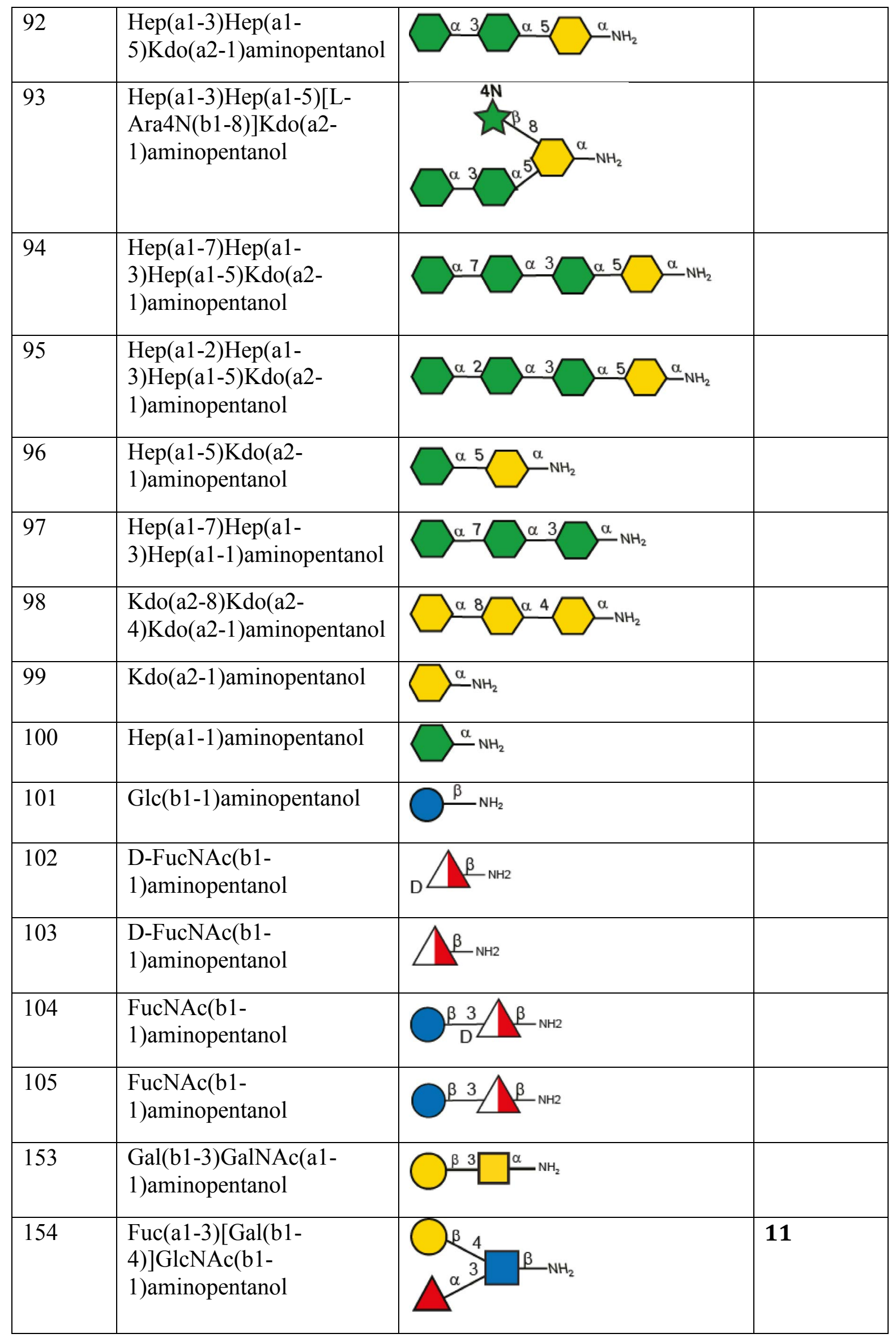




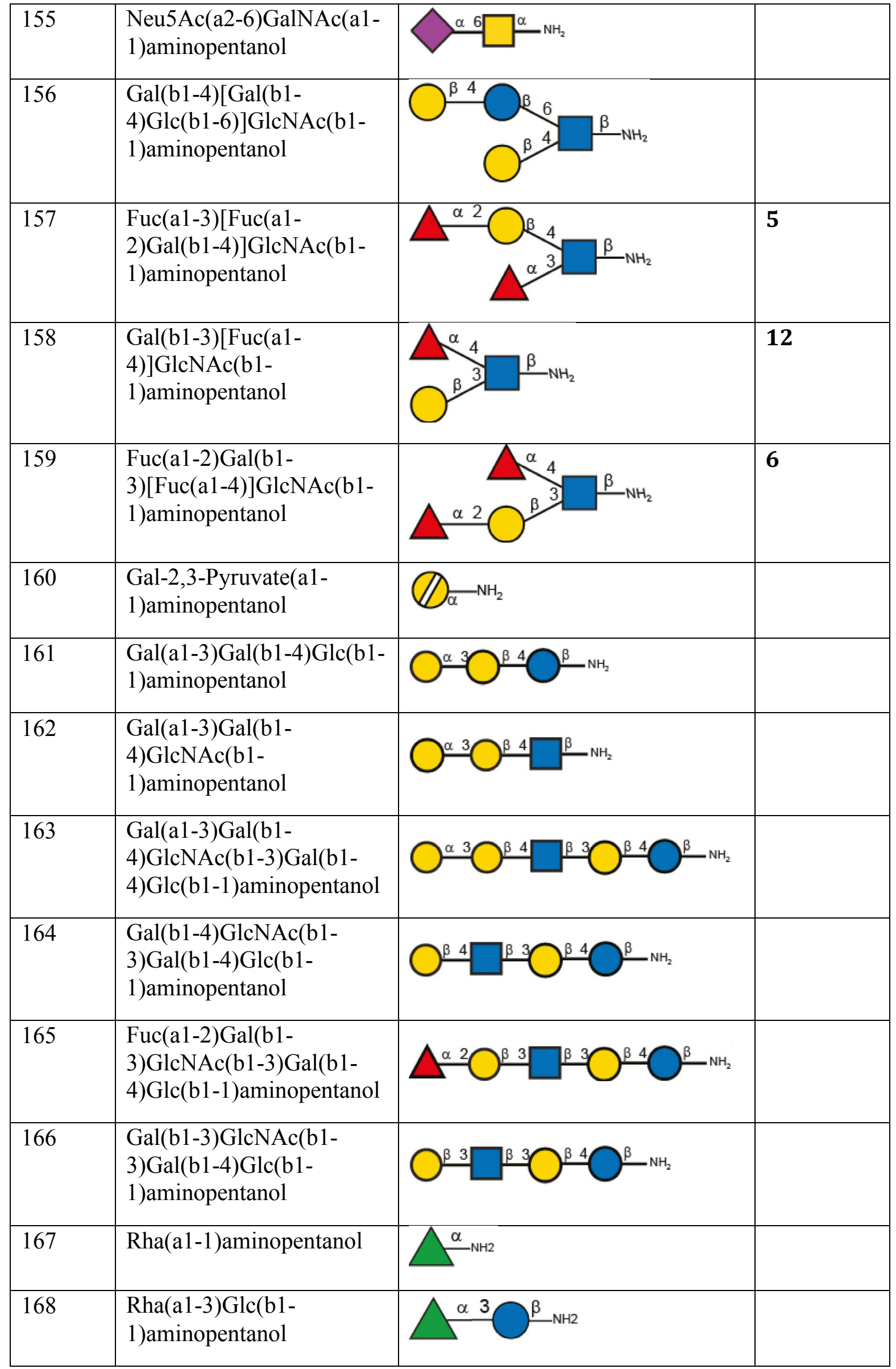




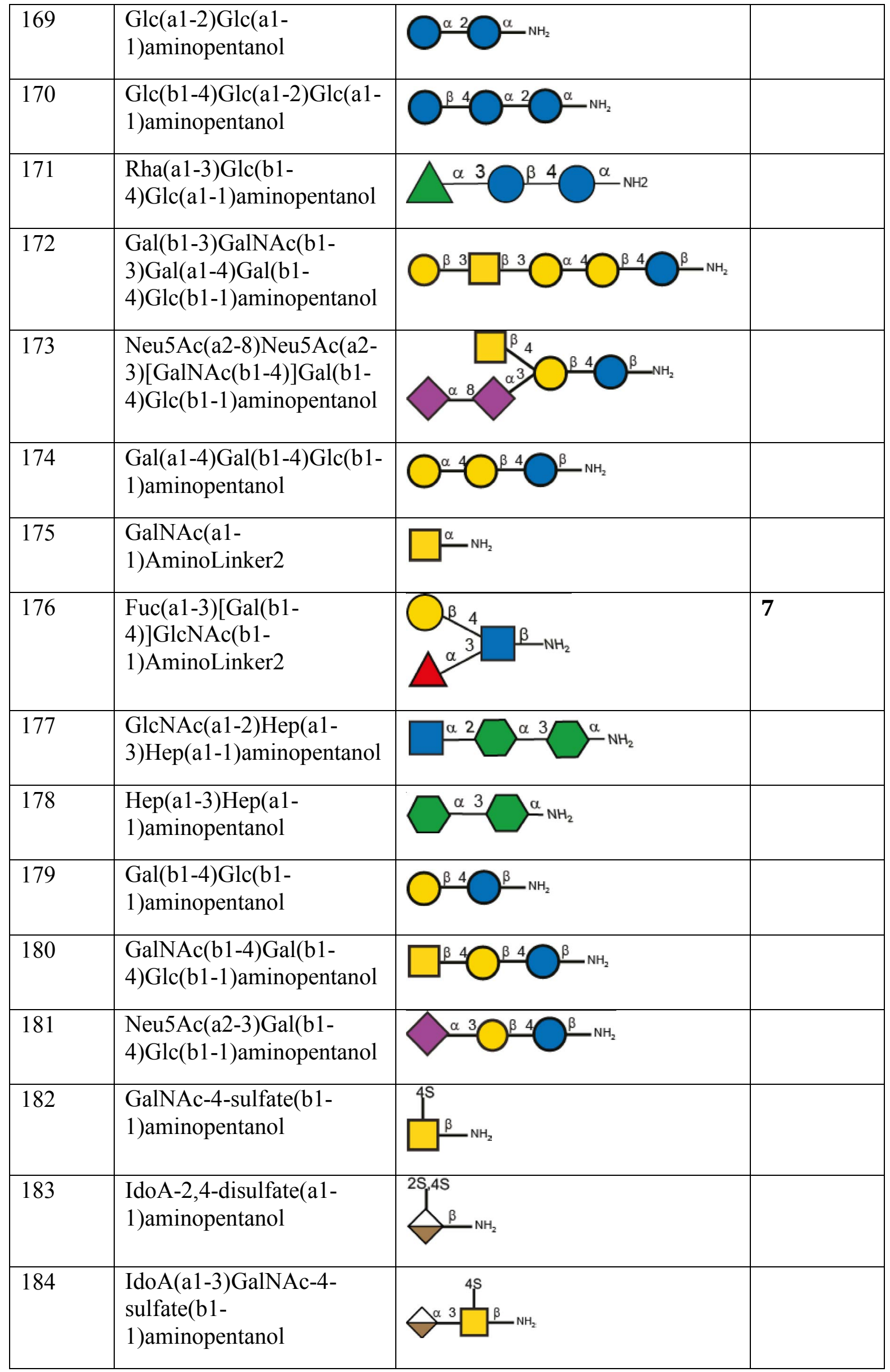




\begin{tabular}{|c|c|c|}
\hline 185 & $\begin{array}{l}\text { IdoA-2-sulfate(a1- } \\
\text { 3)GalNAc-4-sulfate(b1- } \\
\text { 1)aminopentanol }\end{array}$ & $\int_{\alpha 3}^{2 S} \int^{\beta}{ }^{\beta} \mathrm{NH}_{2}$ \\
\hline 186 & $\begin{array}{l}\text { IdoA(a1-3)GalNAc(b1- } \\
\text { 1)aminopentanol }\end{array}$ & $\diamond^{\alpha} \sqrt[3]{{ }^{\beta}}{ }^{\mathrm{NH}_{2}}$ \\
\hline 187 & $\begin{array}{l}\text { GlcA(b1-4)Glc(b1- } \\
\text { 3)GlcA(b1-4)Glc(b1- } \\
\text { 1)aminoethanol }\end{array}$ & \\
\hline 188 & $\begin{array}{l}\text { Glc(b1-3)GlcA(b1- } \\
\text { 4)Glc(b1-1)aminoethanol }\end{array}$ & \\
\hline 189 & GalNAc(a1-1)Thr-Linker & \\
\hline 190 & $\begin{array}{l}\text { Glc(b1-3)Glc(b1- } \\
\text { 3)[Glc(b1-6)]Glc(b1- } \\
\text { 3)Glc(b1-1)aminopentanol }\end{array}$ & \\
\hline 191 & $\begin{array}{l}\text { Glc(b1-3)Glc(b1- } \\
\text { 3)[Glc(b1-6)]Glc(b1- } \\
\text { 3)Glc(b1-3)Glc(b1- } \\
\text { 3)Glc(b1-3)Glc(b1- } \\
\text { 3)Glc(b1-1)aminopentanol }\end{array}$ & \\
\hline 192 & $\begin{array}{l}\text { Glc(b1-3)Glc(b1- } \\
\text { 3)[Glc(b1-6)]Glc(b1- } \\
\text { 3)Glc(b1-3)Glc(b1- } \\
\text { 3)Glc(b1-3)Glc(b1- } \\
\text { 3)Glc(b1-3)Glc(b1- } \\
\text { 3)Glc(b1-3)Glc(b1- } \\
\text { 3)Glc(b1-1)aminopentanol }\end{array}$ & 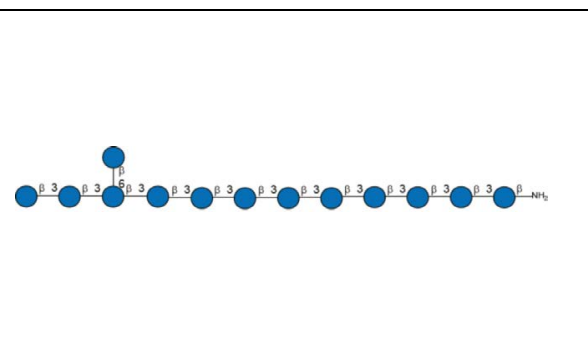 \\
\hline 193 & $\begin{array}{l}\text { Glc(b1-3)Glc(b1-3)Glc(b1- } \\
\text { 3)Glc(b1-3)Glc(b1- } \\
\text { 3)Glc(b1-3)Glc(b1- } \\
\text { 3)Glc(b1-3)Glc(b1- } \\
\text { 3)Glc(b1-3)Glc(b1- } \\
\text { 3)Glc(b1-1)aminopentanol }\end{array}$ & 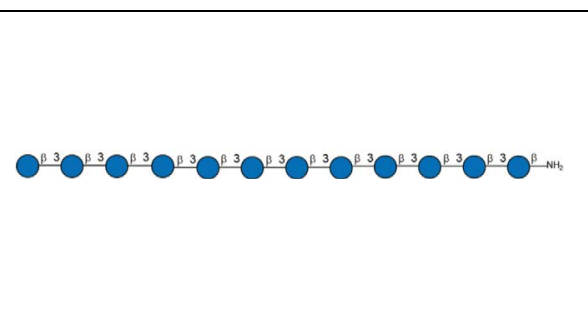 \\
\hline 194 & $\begin{array}{l}\text { L-PneNAc(a1-2)GlcA(b1- } \\
\text { 3)FucNAc(a1-3)D- } \\
\text { FucNAc(b1- } \\
\text { 1)aminopentanol }\end{array}$ & ${ }_{D}^{\alpha 3} \wedge^{\beta}{ }^{N H 2}$ \\
\hline 195 & $\begin{array}{l}\text { Mixture of: D-6d- } \\
\text { xylHexpNAc-4-ulo(b1- } \\
\text { 1)aminopentanol and D- }\end{array}$ & $\bigwedge_{\mathrm{D}}^{\|_{\mathrm{NH} 2}} \Lambda_{\mathrm{D}}^{\beta}{ }_{\mathrm{NH} 2}$ \\
\hline
\end{tabular}




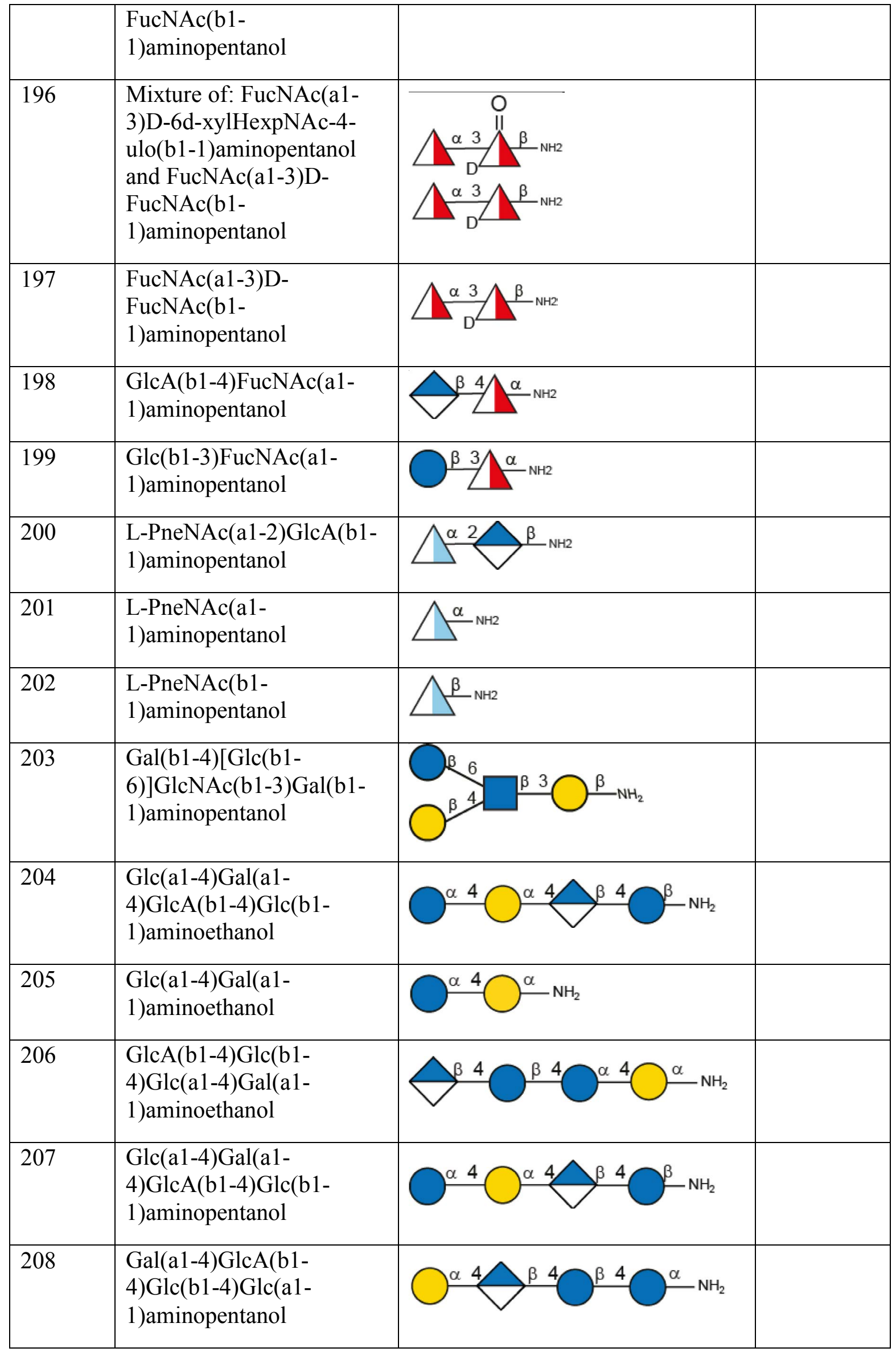




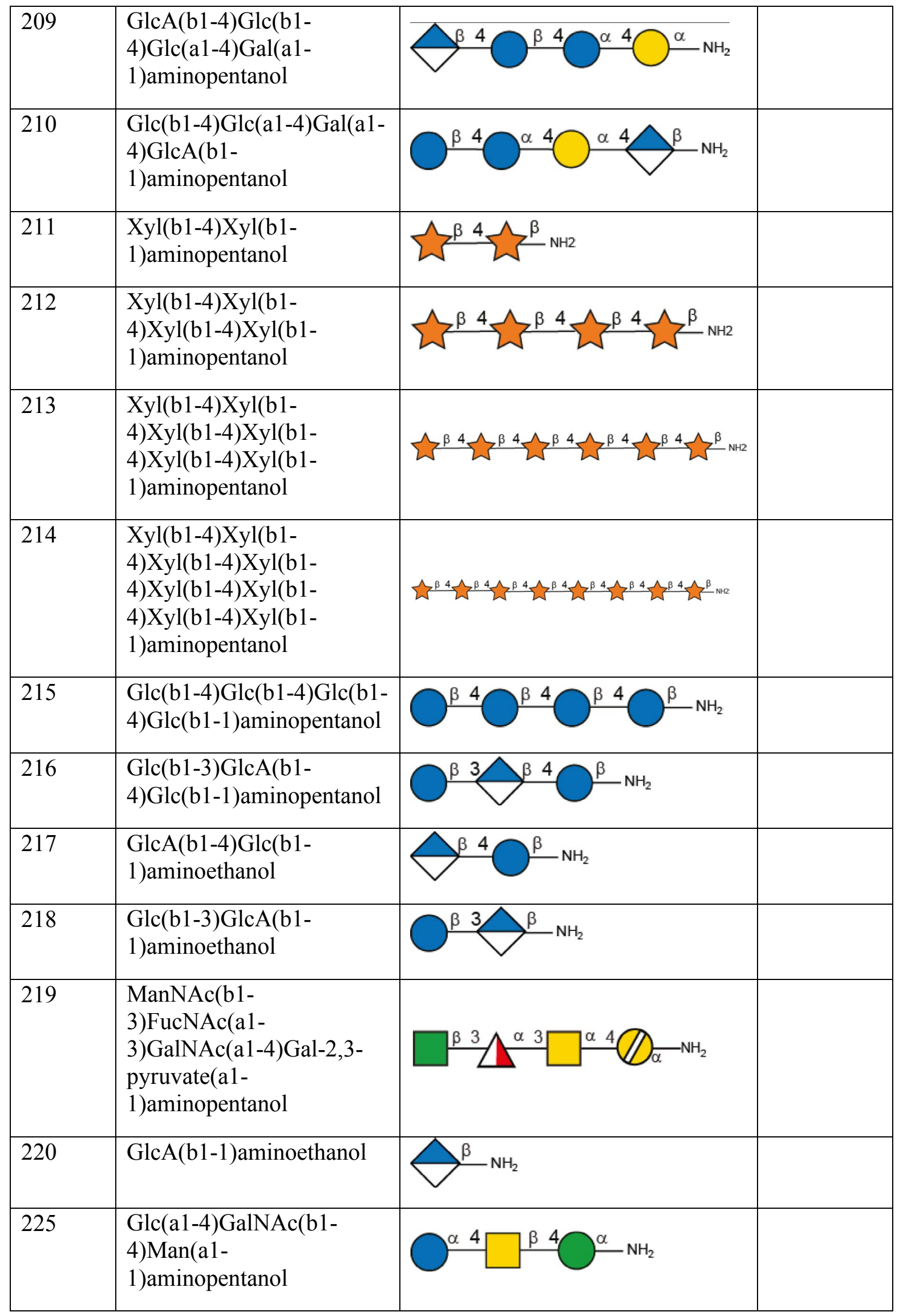




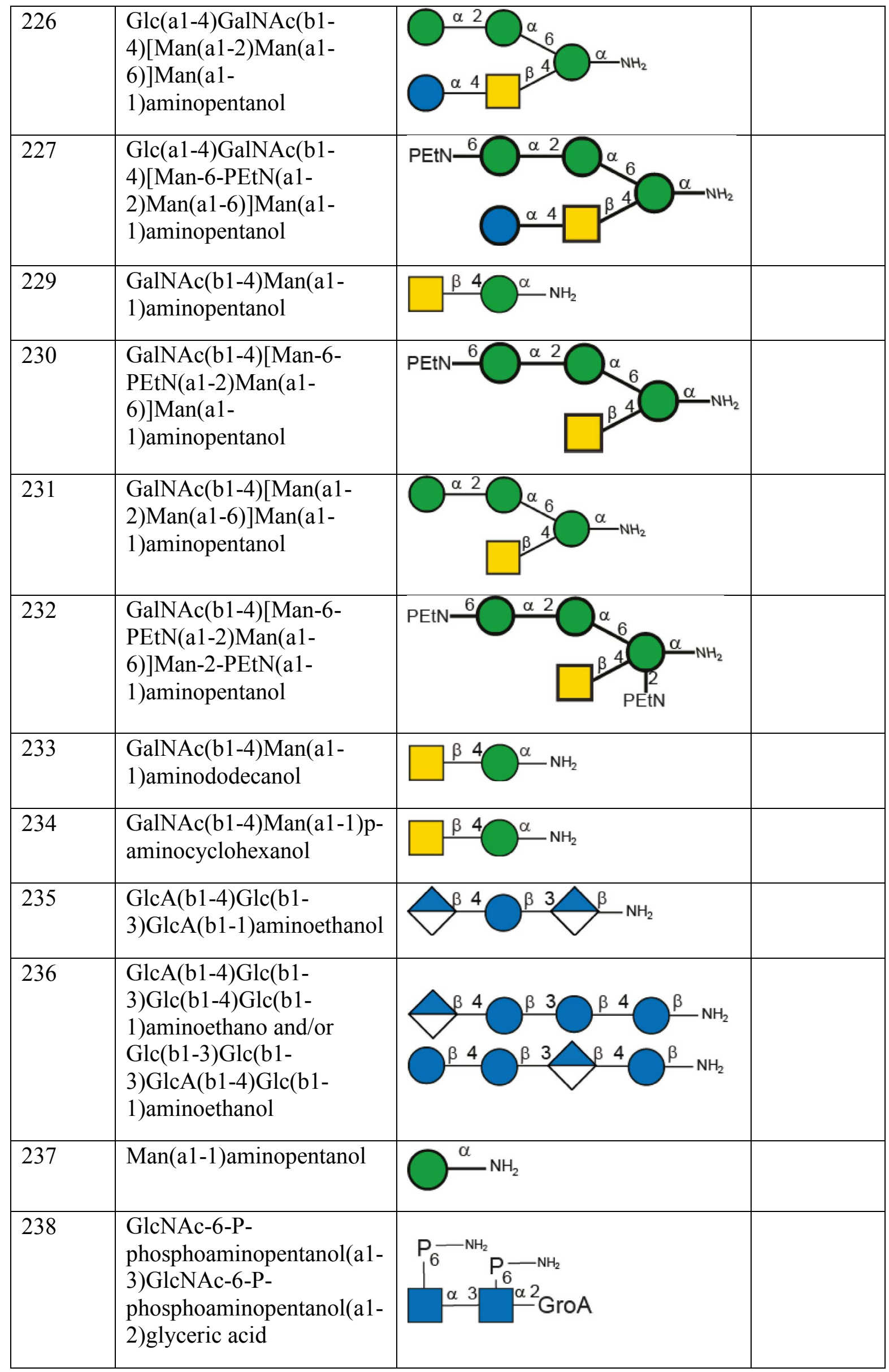




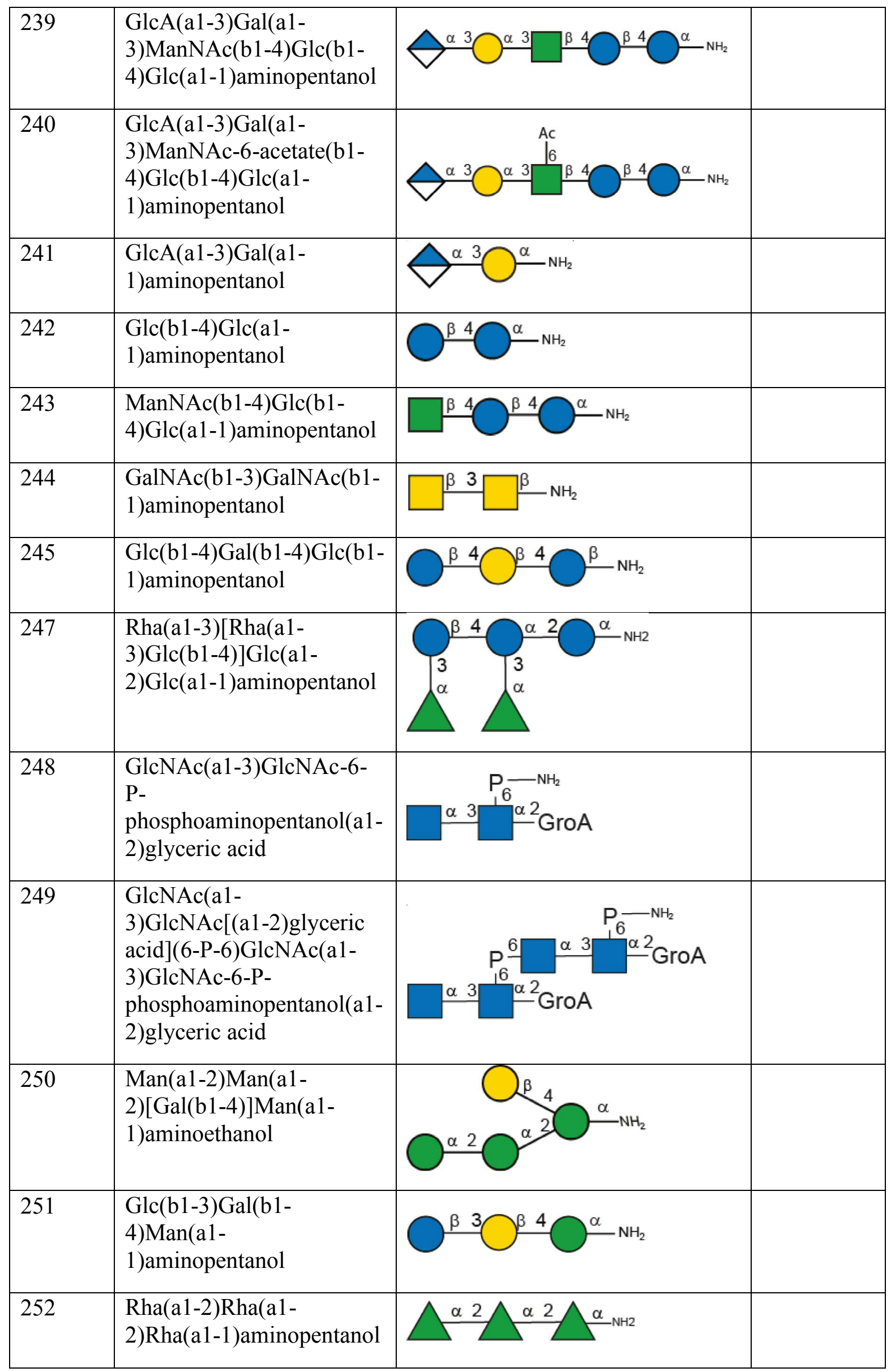




\begin{tabular}{|c|c|c|}
\hline 253 & $\begin{array}{l}\text { GalNAc-2,3- } \\
\text { Oxazolidinone(a1- } \\
\text { 4)GalNAc-2,3- } \\
\text { Oxazolidinone(a1- } \\
\text { 1)aminopentanol }\end{array}$ & $\underbrace{\mathrm{NAC}}_{0}$ \\
\hline 254 & $\begin{array}{l}\text { Glc(a1-2)Glc(a1- } \\
\text { 3)[FucNAc(a1- } \\
\text { 3)GalNAc(b1- } \\
\text { 4)]ManNAcA(b1- } \\
\text { 1)aminopentanol }\end{array}$ & $b_{2}$ \\
\hline 255 & $\begin{array}{l}\text { Glc(a1-2)Glc(a1- } \\
\text { 3)[Gal(a1-3)FucNAc(a1- } \\
\text { 3)GalNAc(b1- } \\
\text { 4)]ManNAcA(b1- } \\
\text { 1)aminopentanol }\end{array}$ & \\
\hline 256 & $\begin{array}{l}\text { D-Araf(a1-3)[D-Araf(a1- } \\
\text { 5)]D-Araf(a1-5)D-Araf(a1- } \\
\text { 1)aminopentanol }\end{array}$ & \\
\hline 257 & $\begin{array}{l}\text { Man(a1-5)D-Araf(a1- } \\
\text { 3)[Man(a1-5)D-Araf(a1- } \\
\text { 5)]D-Araf(a1-5)D-Araf(a1- } \\
\text { 1)aminopentanol }\end{array}$ & \\
\hline 258 & $\begin{array}{l}\text { Man(a1-5)D-Araf(a1- } \\
\text { 3)[Man(a1-5)D-Araf(a1- } \\
\text { 5)]D-Araf(a1-5)D-Araf(a1- } \\
\text { 1)aminopentanol }\end{array}$ & 3Ac,4Ac \\
\hline
\end{tabular}


bioRxiv preprint doi: https://doi.org/10.1101/857730; this version posted November 29, 2019. The copyright holder for this preprint (which was not certified by peer review) is the author/funder, who has granted bioRxiv a license to display the preprint in perpetuity. It is made available under aCC-BY-NC-ND 4.0 International license.

879 Supplementary Table 3: Overview of all glycans on the microarrays in Supplementary

880 Figure 5a,b. For additional information see reference no. 40.

\begin{tabular}{|c|c|c|c|}
\hline $\begin{array}{l}\text { Glycan } \\
\text { ID }\end{array}$ & Name & Structure & $\begin{array}{l}\text { Compound } \\
\text { no. Fig. } \\
\text { S5a/b }\end{array}$ \\
\hline 5 & $\begin{array}{l}\text { Neu5Ac(a2-6)Gal(b1- } \\
\text { 4)GlcNAc(b1- } \\
\text { 3)Gal(b1-4)Glc(b1- } \\
\text { 1)aminohexanol }\end{array}$ & & 16 \\
\hline 6 & $\begin{array}{l}\text { Neu5Ac(a2-3)Gal(b1- } \\
\text { 3)GlcNAc(b1- } \\
\text { 3)Gal(b1-4)Glc(b1- } \\
\text { 1)aminohexanol }\end{array}$ & & 17 \\
\hline 7 & $\begin{array}{l}\text { Fuc(a1- } \\
\text { 3)[Neu5Ac(a2- } \\
\text { 3)Gal(b1- } \\
\text { 4)]GlcNAc(b1- } \\
\text { 3)Gal(b1-4)Glc(b1- } \\
\text { 1)aminohexanol }\end{array}$ & & 18 \\
\hline 8 & $\begin{array}{l}\text { Neu5Ac(a2-6)Gal(b1- } \\
\text { 4)Glc(b1- } \\
\text { 1)aminohexanol }\end{array}$ & & 19 \\
\hline 9 & $\begin{array}{l}\text { Neu5Ac(a2-3)Gal(b1- } \\
\text { 4)Glc(b1- } \\
\text { 1)aminohexanol }\end{array}$ & & 20 \\
\hline 10 & $\begin{array}{l}\text { Neu5Ac(a2-6)Gal(b1- } \\
\text { 4)GlcNAc-6- } \\
\text { sulfate(b1- } \\
\text { 1)aminohexanol }\end{array}$ & & 21 \\
\hline 155 & $\begin{array}{l}\text { Neu5Ac(a2- } \\
\text { 6)GalNAc(a1- } \\
\text { 1)aminopentanol }\end{array}$ & & 22 \\
\hline 173 & $\begin{array}{l}\text { Neu5Ac(a2- } \\
\text { 8)Neu5Ac(a2- } \\
\text { 3)[GalNAc(b1- } \\
\text { 4)]Gal(b1-4)Glc(b1- } \\
\text { 1)aminopentanol }\end{array}$ & & 23 \\
\hline 181 & $\begin{array}{l}\text { Neu5Ac(a2-3)Gal(b1- } \\
\text { 4)Glc(b1- } \\
\text { 1)aminopentanol }\end{array}$ & & 24 \\
\hline
\end{tabular}




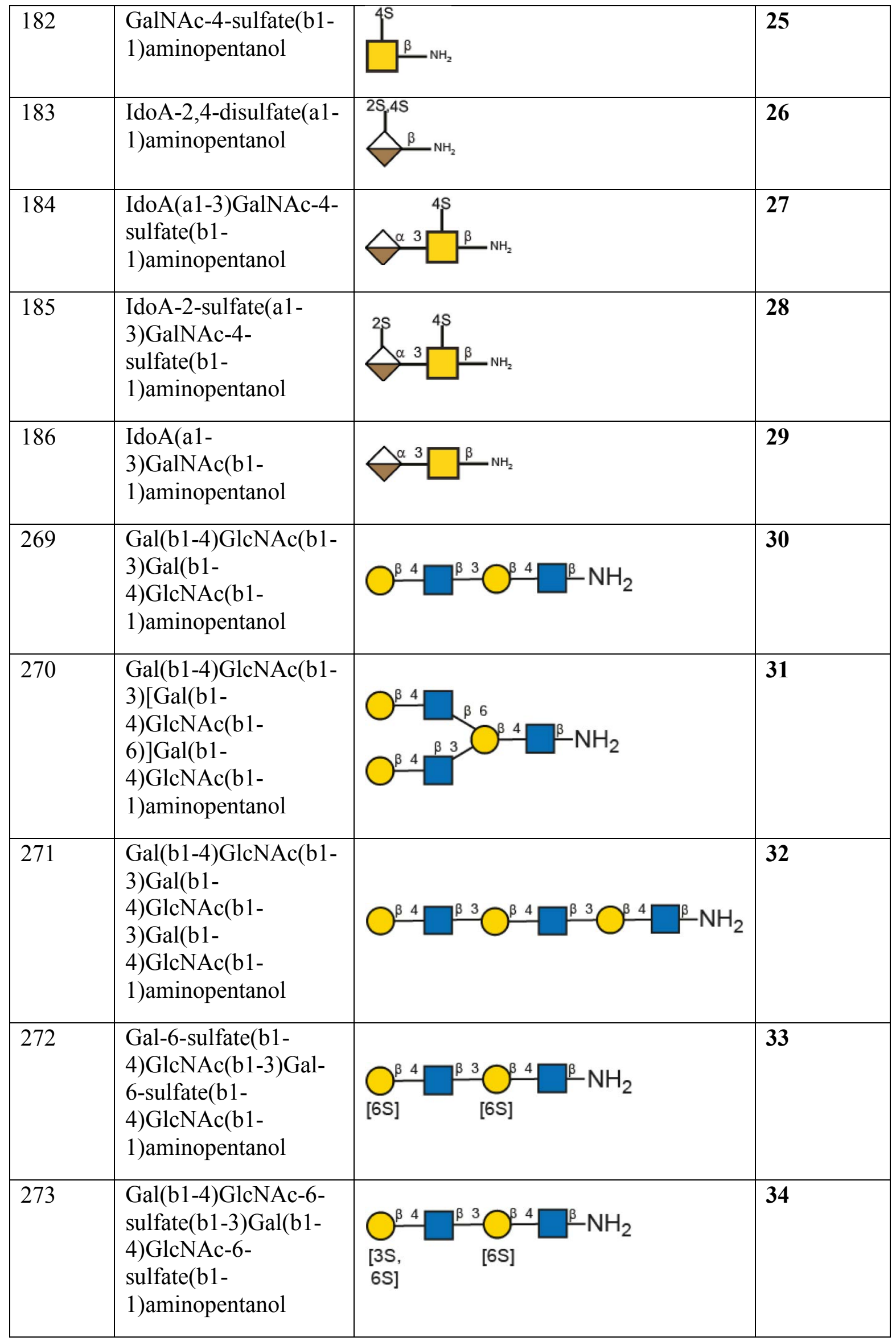


bioRxiv preprint doi: https://doi.org/10.1101/857730; this version posted November 29, 2019. The copyright holder for this preprint (which was not certified by peer review) is the author/funder, who has granted bioRxiv a license to display the preprint in perpetuity. It is made available under aCC-BY-NC-ND 4.0 International license.

\section{1}

\begin{tabular}{|c|c|c|c|}
\hline 274 & $\begin{array}{l}\text { Gal-3,6-disulfate(b1- } \\
\text { 4)GlcNAc(b1-3)Gal- } \\
\text { 6-sulfate(b1- } \\
\text { 4)GlcNAc(b1- } \\
\text { 1)aminopentanol }\end{array}$ & $\bigcirc^{\beta 4} \square_{[6 \mathrm{~S}]}^{\beta 3} \bigcirc^{\beta 4} \underbrace{\beta}_{[6 \mathrm{~S}]} \mathrm{NH}_{2}$ & 35 \\
\hline 275 & $\begin{array}{l}\text { Gal-6-sulfate(b1- } \\
\text { 4)GlcNAc-6- } \\
\text { sulfate(b1-3)Gal-6- } \\
\text { sulfate(b1-4)GlcNAc- } \\
\text { 6-sulfate(b1- } \\
\text { 1)aminopentanol }\end{array}$ & $\mathrm{C}_{[6 \mathrm{~S}]}^{\beta 4} \square_{[6 \mathrm{~S}]}^{\beta 3} \mathrm{CWS}_{[6 \mathrm{~S}]}^{\beta 4} \square^{\beta} \mathrm{NH}_{2}$ & 36 \\
\hline
\end{tabular}

